\title{
FONTES VEGETAIS NATURAIS DE ANTIOXIDANTES
}

\author{
Alane Cabral de Oliveira, Iara Barros Valentim e Marília Oliveira Fonseca Goulart* \\ Instituto de Química e Biotecnologia, Universidade Federal de Alagoas, 57072-970 Maceió - AL, Brasil \\ Cícero Alexandre Silva \\ Centro de Ciências Agrárias, Universidade Federal de Alagoas, 57100-000 Rio Largo - AL, Brasil \\ Etelvino José Henriques Bechara \\ Departamento de Bioquímica, Instituto de Química, Universidade de São Paulo, 05508-000 São Paulo - SP/Departamento de Ciências e da \\ Terra, Universidade Federal de São Paulo, 09972-270 Diadema - SP, Brasil \\ Maria Teresa Salles Trevisan \\ Departamento de Química Orgânica e Inorgânica, Universidade Federal do Ceará, 60451-970 Fortaleza - CE, Brasil
}

Recebido em 19/1/09; aceito em 17/3/09; publicado na web em 2/4/09

\begin{abstract}
VEGETALS AS NATURAL SOURCES OF ANTIOXIDANTS. Growing knowledge on the health-promoting impact of antioxidants in everyday foods, combined with the assumption that a number of common synthetic preservatives may have hazardous side effects has led to increased investigations in the field of natural antioxidants, principally those found in plants. Food industries normally discard plant residues that could benefit the human health and diminish undesirable environmental impact. Once estimated the content of antioxidants in these residues, advantageous economical and social alternatives to the discard are possible, for example, their use for preparation of nutraceuticals to be offered to low-income populations. We present here a broad, although not complete, account of the continuously growing knowledge on the antioxidant capacity of whole fruits, seeds and peels, cereals, vegetal oils and aromatic plants, at several physical forms, as well as a description of the usual methods for evaluating their antioxidant capacity and examples of agroindustrial processes that could be harnessed for the production of antioxidant supplement food, along with research perspectives in the area.
\end{abstract}

Keywords: oxidative stress; antioxidant capacity; agroindustrial wastes.

\section{INTRODUÇÃO}

Há fatores de diversas ordens associados ao estresse redox, como: hábitos de vida considerados inapropriados (consumo de álcool, tabagismo, dieta inadequada, exercício físico realizado de forma extrema e exposição à radiação não ionizante ultravioleta e outras ondas curtas); condições ambientais impróprias (temperatura elevada e poluição ambiental, domiciliar e ocupacional); envelhecimento e estados psicológicos que provoquem estresse emocional. Há também patologias crônicas (diabetes mellitus, hipertensão arterial, câncer, entre outras) e patologias degenerativas (Mal de Alzheimer e Mal de Parkinson) associadas ao estresse redox. ${ }^{1}$

Estresse redox é comumente definido como o desequilíbrio entre a produção de espécies reativas de oxigênio, nitrogênio e enxofre, entre outras, e a remoção destas pelos sistemas químicos e enzimáticos de defesa antioxidante e, também, pelo reparo enzimático das biomoléculas lesadas. ${ }^{2,3}$ As espécies reativas mais estudadas nos sistemas biológicos incluem as espécies reativas de oxigênio, as espécies reativas de nitrogênio, os radicais derivados de tióis ( $\mathrm{RS}^{\bullet}$ ), as espécies reativas de cloro, as espécies reativas de carbono e complexos de metais de transição, principalmente $\mathrm{Fe}, \mathrm{Cu}, \mathrm{Mn}$ e $\mathrm{Cr}^{1,3,4}$

Outros íons metálicos, sem atividade redox direta, também podem afetar o balanço oxidativo, como os íons de metais pesados $(\mathrm{Pb}, \mathrm{Cd})$ e trivalentes $(\mathrm{Bi}, \mathrm{Al})$, que são capazes de se ligar fortemente aos grupos fosfatos dos fosfolipídios de membranas celulares, diminuindo sua fluidez e, consequentemente, aumentando sua peroxibilidade. $\mathrm{Na}$ medida em que íons divalentes ( $\mathrm{Mg}, \mathrm{Ca}, \mathrm{Zn})$ são cofatores de proteínas e enzimas envolvidas na maquinaria redox celular, estes também podem afetar o balanço oxidativo. ${ }^{1}$

*e-mail: mofg@qui.ufal.br
Espécies reativas incluem, em cada grupo, não só os radicais $\left(\mathrm{O}_{2}^{--},{ }^{\circ} \mathrm{OH}, \mathrm{NO}^{*}\right)$, mas também intermediários neutros ou carregados $\left(\mathrm{H}_{2} \mathrm{O}_{2}, \mathrm{ONOO}^{-}\right)$e outras espécies capazes de formar radicais livres no organismo humano $\left({ }^{1} \mathrm{O}_{2}{ }^{*}, \mathrm{O}_{3}, \mathrm{Fe}, \mathrm{Cu}\right) .{ }^{1,4}$

Dentre os antioxidantes enzimáticos mais estudados, destacam-se as superóxido dismutases, consideradas como a linha de frente de defesa antioxidante, embora possam exibir atividade peroxidásica, na presença de excesso de $\mathrm{H}_{2} \mathrm{O}_{2}$; destacam-se também a catalase e as glutationas peroxidases, encarregadas de reduzir peróxidos geradores de radicais ${ }^{\circ} \mathrm{OH}$ e ${ }^{\circ} \mathrm{OR}$, respectivamente. ${ }^{3}$

Quanto aos antioxidantes de baixo peso molecular (antioxidantes “químicos"), devem-se incluir algumas vitaminas (C, E e A), outros produtos naturais (ex.: carotenoides, flavonoides, outros polifenois, furanoides e tióis) e produtos sintéticos (ex.: Ebselen, $N$-acetilcisteína e Trolox). É interessante notar que espécies carbonílicas no estado triplete, produzidas na termólise de dioxetanos e dismutação de radicais alcoxilas e peroxilas, formadas com altos rendimentos durante a peroxidação lipídica e outras oxidações biológicas, têm sido negligenciadas na literatura apesar de, in vitro, terem exibido reatividade similar à de radicais alcoxila. ${ }^{5,6}$

Espécies reativas são formadas continuamente durante os processos metabólicos - normais ou patogênicos - ou são provenientes de fontes exógenas físicas e químicas. Tais espécies atuam como mediadores da transferência de elétrons e em vários processos bioquímicos, ${ }^{7}$ como a fagocitose, fenômeno em que espécies reativas de oxigênio, $\mathrm{H}_{2} \mathrm{O}_{2}, \mathrm{ClO}^{-} \mathrm{e}^{1} \mathrm{O}_{2}{ }^{*}$, são produzidas para eliminar o agente agressor por oxidação. Porém, quando em concentração excedente ao normal, essas espécies podem causar duas categorias de efeitos potencialmente importantes: a) danos celulares, ao atacar membranas, proteínas, polissacarídeos e ácidos nucleicos, com consequente alteração funcional e prejuízo das funções vitais em diversos tecidos 
- adiposo, vascular e cerebral, e órgãos, como músculo e fígado, ${ }^{8}$ ocasionando eventualmente algumas doenças, ${ }^{3,9-11}$ e b) ativação de caminhos de sinalização específicos. . $^{4,12}$

Estudos epidemiológicos têm mostrado que dietas ricas em frutas e verduras estão associadas a uma menor incidência de doenças crônicas e degenerativas, ${ }^{14-18}$ embora prova definitiva de que suplementos antioxidantes possam prevenir doenças crônicas não tenha sido obtida ou consistentemente suportada pelos testes de intervenção encontrados na literatura. Há muita controvérsia nessa área de pesquisa, indicando a necessidade de obtenção de evidências inequívocas a respeito da eficácia, segurança e dosagem apropriada de antioxidantes em relação a doenças crônicas. ${ }^{19}$ Assim, apesar de não haver comprovação científica definitiva, é prudente e aconselhável, em termos de saúde pública, aumentar o consumo de alimentos vegetais ${ }^{19} \mathrm{e}$ seguir uma dieta similar à denominada "dieta do Mediterrâneo". ${ }^{20}$

Um dos principais aspectos relacionados ao efeito protetor desses alimentos tem sido atribuído, em parte, à presença de compostos antioxidantes, dentre os quais se destacam os compostos fenólicos, além dos bem conhecidos -caroteno, vitamina $\mathrm{C}$ e vitamina E..$^{21-23}$

$\mathrm{O}$ termo antioxidante tem natureza multiconceitual. No entanto, de maneira geral e no contexto deste trabalho, 'antioxidante' pode ser definido como uma família heterogênea de moléculas naturais, que, presentes em baixas concentrações, comparativamente às biomoléculas que supostamente protegeriam, podem prevenir ou reduzir a extensão do dano oxidativo. ${ }^{1,24}$

Antioxidantes de baixo peso molecular podem ser sintetizados no próprio organismo ou ser oriundos da dieta. Estão presentes em número e concentração maiores que os antioxidantes enzimáticos e distribuídos em ambientes lipofílicos e hidrofílicos. Nenhum antioxidante, isoladamente, reúne todas as características de um bom antioxidante, ${ }^{25}$ assim descritas: deve ser um composto biológico naturalmente presente em tecidos animais; deve ser ativo na proteção de moléculas de proteínas e lipídios; deve ter uma boa biodisponibilidade, após administração oral e parenteral; deve ter meia-vida longa; deve ser ativo no espaço intra e extracelular e, deve ser capaz de cruzar a membrana celular intacto.

Mais especificamente, antioxidantes agem nos organismos vivos por meio de diferentes mecanismos. Dentre estes, podem ser citados: a complexação de íons metálicos, a captura de radicais livres, a decomposição de peróxidos, a inibição de enzimas responsáveis pela geração de espécies reativas de oxigênio e nitrogênio e a modulação de vias sinalizadoras celulares. ${ }^{23}$

A pesquisa de métodos reveladores e confiáveis para detecção precoce e prevenção de alterações no equilíbrio redox celular e de tecidos específicos, por meio da análise de "biomarcadores", revestese, atualmente, de forte interesse científico e clínico. ${ }^{3} \mathrm{O}$ desenvolvimento crescente de técnicas de ressonância magnética nuclear de alta resolução, de ressonância paramagnética de spin e da síntese de spin traps (capturadores de spin), das várias modalidades instrumentais e técnicas de espectrometria de massas, de imageamento com sondas fluorescentes, associadas a técnicas de separação com alta resolução (cromatografia líquida de alta eficiência e eletroforese capilar) têm crucial importância na análise destes parâmetros. ${ }^{26}$ De posse desses dados, busca-se compreender os mecanismos moleculares que sublinham o estresse redox e propor medicamentos ou alternativas nutricionais (alimentos ou nutrientes específicos) que possam diminuir a ação deletéria dessas espécies reativas sobre a saúde da população humana. ${ }^{27-30}$

Em termos alimentares, a deterioração de óleos e gorduras é responsável pelos odores e sabores rançosos, com consequente decréscimo da qualidade e segurança nutricionais, causado pela formação de produtos secundários, potencialmente tóxicos. Assim, a adição de antioxidantes é requerida para preservar sabor e odor, além de evitar a destruição de vitaminas. Dentre os antioxidantes sintéticos mais utilizados para preservar alimentos, constam o hidroxianisol butilado (BHA), o hidroxitolueno butilado (BHT), o galato de propila, a tercbutil-hidroquinona e os sorbatos (2,4-hexadienoatos). ${ }^{31}$ A substituição de antioxidantes sintéticos por naturais pode apresentar vantagens devido a implicações na área de saúde e na funcionalidade. Nota-se, por exemplo, que a maior solubilidade dos antioxidantes naturais tanto em água como em óleo é útil na preparação de emulsões e outras formulações, como os hidrogéis. ${ }^{31} \mathrm{Na}$ utilização de antioxidantes naturais, há vantagem também no nível preservacionista, na medida em que as indústrias alimentícias produzem resíduos que poderiam ter um destino muito mais benéfico, favorecendo o homem e o meio ambiente. Por exemplo, muitos frutos comestíveis são processados para fabricação de sucos naturais, sucos concentrados, doces em conserva, polpas e extratos. Esses frutos possuem sementes e cascas, fontes naturais de antioxidantes, que são muitas vezes descartadas em vez de serem utilizadas, evitando o desperdício de alimentos.

Dessa forma, no presente artigo, apresenta-se ampla, embora não completa, revisão bibliográfica da capacidade antioxidante de determinados produtos de origem vegetal, como frutas, sementes, cereais, óleos e plantas aromáticas, em sua totalidade ou de partes dos mesmos, sob diversas formas de processamento.

Descrevem-se, também, os principais métodos de análise da capacidade antioxidante frente aos oxidantes biológicos mais reativos, mostrando exemplos de aproveitamento de vegetais, como os resíduos agroindustriais, e abordam-se questões dietéticas da suplementação com os antioxidantes.

\section{FONTES NATURAIS DE ANTIOXIDANTES}

\section{Frutas e derivados}

Antioxidantes, como a vitamina $\mathrm{C}$, a vitamina $\mathrm{E}$, os carotenoides e flavonoides, estão presentes como constituintes dietéticos. ${ }^{23,32} \mathrm{~A}$ Tabela 1 lista frutas e derivados como fontes naturais de antioxidantes. Vários aspectos relativos aos antioxidantes naturais têm sido objeto de investigação. ${ }^{33-42}$ Levando-se em consideração a interferência de aspectos químicos e físicos, estudos mostram a influência do processamento e do tempo de armazenamento sobre o conteúdo de polifenóis em morangos. ${ }^{39}$ Após a colheita, muitas frutas e vegetais perdem seus antioxidantes e o modo de acondicionamento utilizando citocininas leva a mudanças, principalmente nos alimentos com alta capacidade fermentativa, como o brócolis. ${ }^{40}$ Klimczak e colaboradores ${ }^{41}$ avaliaram o efeito da estocagem no conteúdo de polifenóis, vitamina $\mathrm{C}$ e a atividade antioxidante de sucos comerciais de laranja.-

\section{Verduras, hortaliças e temperos}

Vários estudos têm evidenciado o potencial antioxidante de uma larga variedade de vegetais (Tabela 2). ${ }^{43-45}$

\section{Bebidas}

Vinhos contêm uma ampla variedade de compostos polifenólicos, em especial resveratrol e seus derivados (Tabela 3). ${ }^{46,47}$ De Beer e colaboradores ${ }^{47}$ avaliaram o conteúdo de fenóis e ácido ascórbico, além de pesquisarem a inibição da peroxidação lipídica in vitro de vinhos tinto e branco produzidos no sul da África. Além de vinhos, estudos registram a atividade antioxidante em outros tipos de bebidas alcoólicas, como licor e cerveja ${ }^{48,49}$ Chá verde e chá preto têm sido extensivamente estudados quanto às propriedades antioxidantes frente a uma variedade de espécies reativas..$^{50,51}$ Turkmen e colaboradores ${ }^{52}$ estudaram o efeito do tipo de solvente utilizado no processo de 
Tabela 1. Frutas e derivados como fontes naturais de antioxidantes

Fontes
Framboesa, amora preta, groselha vermelha,
groselha espinhosa e cereja
Ameixa, morango, carambola, goiaba, uva,
maçã, manga, kiwi, melão, mamão, abacate,
coco, melancia, banana, laranja, sapoti, rambu-
tan, entre outras

Baguaçu e jambolão

Principais resultados

Dentre as frutas estudadas, a cereja é considerada aquela com maior fonte de antioxidantes, podendo ser empregada como suplemento alimentar.

A capacidade antioxidante das frutas estudadas variou de acordo com a espécie, de $0,06 \%$ para sapoti até $70,2 \%$ para rambutan.

O extrato metanólico do baguaçu apresentou elevado conteúdo de fenóis (896,7 35 mg $100 \mathrm{~g}^{-1}$ ) quando comparado com outros frutos em bagas e, também, com o jambolão $\left(229,6 \mathrm{mg} 100 \mathrm{~g}^{-1}\right)$.

Laranja, maçã, abacaxi e uva A vitamina $\mathrm{C}$ foi responsável por grande parte da capacidade antioxidante no suco de laranja e menos que $5 \%$ no suco da maçã e abacaxi. Nestes últimos, a maior contribuição foi decorrente da quantidade de fenóis.

Polpa congelada de amora, uva, açaí, goiaba, acerola, morango, abacaxi, manga, graviola, cupuaçu e maracujá

\section{Mangas}

As polpas congeladas de acerola, açaí e morango foram as que apresentaram os maiores valores de fenóis: 580,1; 136,8 e 132,1 mg $100 \mathrm{~g}^{-1}$, respectivamente.

Todos os extratos (casca, sementes, folhas e cascas de frutas) dos 16 cultivares foram analisados quanto à sua alta capacidade antioxidativa, baseada no ensaio HX/XO. Os compostos fenólicos: mangiferina, penta- $O$-galoil-glicosídeo, ácido gálico e galato de metila foram também avaliados por DPPH', FRAP e ORAC. A mangiferina apresentou-se em maior concentração nas folhas jovens de Coité $(172 \mathrm{~g} / \mathrm{kg})$, casca de Momika (107 g/kg) e em folhas velhas de Itamaraká $(94 \mathrm{~g} / \mathrm{kg})$.

Mangas

Doze flavonoides e xantonas foram identificados em polpas, cascas e caroço.

A polpa, casca e caroço da variedade Ubá apresentaram elevada atividade antioxidante.

Morangos

Estocados entre 5 ou $10{ }^{\circ} \mathrm{C}$ mostraram elevada capacidade antioxidante, conteúdo total de fenóis e antocianinas, quando comparados com aqueles estocados a $0{ }^{\circ} \mathrm{C}$.

Brócolis

O modo de acondicionamento utilizando citocininas, leva a mudanças, principalmente, nos alimentos com alta capacidade fermentativa, como brócolis.

Sucos comerciais de laranja Observou-se diminuição no conteúdo de polifenois e vitamina $\mathrm{C}$ após estocagem, o que se refletiu na diminuição da capacidade antioxidante das amostras estudadas.

Polpa e sementes de romã Os extratos aquosos, tanto da polpa quanto das sementes, apresentaram as maiores porcentagens de inibição da oxidação: 87,31 e 93,08\%, respectivamente.

Ref.

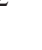

(1)

Tabela 2. Verduras e hortaliças como fontes naturais de antioxidantes

\begin{tabular}{ll}
\hline Fontes & Principais resultados \\
\hline Couve, espinafre, cenoura e cebola & $\begin{array}{l}\text { Cebola e espinafre apresentaram a maior capacidade antioxidante quando } \\
\text { comparados com os outros vegetais estudados. }\end{array}$ \\
\hline Alface & $\begin{array}{l}\text { Demonstrou-se que a alface pode servir como fonte dietética natural de anti- } \\
\text { oxidantes de natureza fenólica. }\end{array}$ \\
\hline $\begin{array}{l}\text { Alface crespa, lisa, batata inglesa, cebola } \\
\text { branca e roxa, cenoura e chuchu }\end{array}$ & $\begin{array}{l}\text { Ação antioxidante moderada (60-70\%) foi exibida pelos extratos da alface } \\
\text { lisa, cebola branca e couve-flor, enquanto que os do chuchu, cenoura, pepino, } \\
\text { tomate e vagem, com atividade inferior a 60\%, foram considerados com fraca } \\
\text { ação antioxidante. }\end{array}$ \\
\hline
\end{tabular}

extração sobre o conteúdo de fenóis e a capacidade antioxidante de chá preto e chá mate, na Turquia (Tabela 3).

\section{Plantas e temperos}

A Tabela 4 lista vários dos estudos feitos a partir de plantas e temperos. Muitos dos princípios ativos em plantas medicinais são compostos fenólicos. Existe um grande número de trabalhos na literatura que descrevem a atividade antioxidante de ervas, plantas medicinais e temperos. ${ }^{54-66}$

Em particular, o pólen apícola é um aglomerado de pólen de flores de várias fontes vegetais, que é coletado pelas abelhas e misturado 
Tabela 3. Bebidas como fontes naturais de antioxidantes

\begin{tabular}{ll}
\hline Fontes naturais de antioxidantes & Principais resultados \\
\hline Vinhos tinto e branco & $\begin{array}{l}\text { Foi observado que o vinho tinto apresenta uma proteção maior quanto à per- } \\
\text { oxidação lipídica, e isto foi atribuído principalmente ao conteúdo de fenóis } \\
\text { das amostras analisadas. }\end{array}$ \\
\hline Licor de noz verde & $\begin{array}{l}\text { A capacidade antioxidante do licor analisado apresentou correlação direta com } \\
\text { o conteúdo total de fenóis, total de taninos e não taninos. O estudo mostrou } \\
\text { ainda não haver diferença significativa entre licores com tempos de armaze- } \\
\text { namento diferentes. }\end{array}$ \\
\hline Cerveja & $\begin{array}{l}\text { Foi capaz de induzir aumento significativo da capacidade antioxidante do plasma } \\
1 \text { h após ingestão, retornando aos níveis basais, 2 h depois. }\end{array}$ \\
\hline Chá preto e chá verde & $\begin{array}{l}\text { Extratos aquosos de chás preto e verde mostraram ação capturadora de espé- } \\
\text { cies reativas de oxigênio, como o oxigênio singleto, ânion-radical superóxido } \\
\text { e radical hidroxila. }\end{array}$ \\
\hline Chá preto & $\begin{array}{l}\text { O chá preto mostra ações de inibição da geração de espécies reativas, além de } \\
\text { sequestro das mesmas e quelação de metais de transição, ações essas atribuídas, } \\
\text { em grande parte, ao conteúdo de catequinas. }\end{array}$ \\
\hline Chá preto e chá mate & $\begin{array}{l}\text { Uma mistura contendo 15\% do extrato etanólico do chá mate e } 50 \% \text { do ex- } \\
\text { trato de chá preto em acetona apresentou grande atividade antioxidante. Os } \\
\text { resultados mostraram que solventes com diferentes polaridades apresentam } \\
\text { efeito significativo sobre o conteúdo de fenóis e a capacidade antioxidante das } \\
\text { amostras analisadas. }\end{array}$ \\
\hline
\end{tabular}

com néctar e secreções das glândulas hipofaringeanas, que contêm as enzimas $\alpha$ e $\beta$-glicosidase. Este aglomerado contém nutrientes, como carboidratos, proteínas, aminoácidos, lipídios, vitaminas e minerais, além de carotenoides, flavonoides e fitosteróis, o que justifica a sua utilização como alimento alternativo e/ou suplemento alimentar. Pólens apícolas mostraram-se altamente promissores, devido à sua alta capacidade antioxidante. ${ }^{54}$

Não menos interessantes foram os achados do grupo de E. Carlini ${ }^{60}$ sobre a elevada proteção antioxidante cerebral de extratos da planta "nó-de-cachorro" (Hereropteris aphrodisiaca), administrados a ratos velhos e a ratos jovens, sendo então comparados os resultados de cada grupo de animais. Essa planta é largamente empregada na medicina popular brasileira como tônico e contra debilidade geral do sistema motor e das capacidades mentais, e é supostamente dotada de propriedades estimulantes e afrodisíacas. ${ }^{60}$

As propriedades antioxidantes dos extratos de alecrim (Rosmarinus officinalis, Labiatae) têm recebido considerável atenção. $\mathrm{Na}$ indústria de alimentos, seus efeitos antioxidantes têm se mostrado superiores aos do antioxidante sintético BHA e semelhantes aos do BHT. Comercialmente, tem sido usado em combinação com tocoferóis, observando-se sinergismo entre o alecrim e o $\alpha$-tocoferol (o extrato de alecrim regenera o tocoferol). ${ }^{62}$

\section{Sementes}

Sementes são fontes alternativas naturais de antioxidantes (Tabela 5$){ }^{67-73}$

\section{Fontes residuais}

O grande interesse na substituição de antioxidantes alimentares sintéticos por naturais despertou intensa procura por materiais vegetais brutos para a identificação de novos antioxidantes. As reações de oxidação não são de interesse exclusivo das indústrias alimentícias, na medida em que influenciam a produção de outros bens oxidáveis, como cosméticos, farmacêuticos e plásticos. Moure e colaboradores $^{32}$ publicaram uma revisão abordando a extração de compostos antioxidantes (principalmente polifenóis) de resíduos industriais e da agroindústria, nos quais identificaram importantes antioxidantes.

A Tabela 6 reúne resultados de fontes naturais atrativas de antioxidantes a partir de resíduos da agricultura e da indústria alimentícia. ${ }^{74-93}$ Algumas características especiais são especificadas, a seguir.

É interessante notar que o estado redox de cascas de maçã varia conforme os diferentes genótipos, o tempo e o tipo de estocagem. ${ }^{85}$ Ainda em relação a resíduos de cascas de frutas, Ajila e colaboradores ${ }^{86}$ estudaram compostos bioativos e o potencial antioxidante de extratos provenientes da casca de manga, relatando uma alta atividade antioxidante, segundo diferentes sistemas de medida. Eles sugeriram, em função desta importante propriedade, o uso de casca de manga como nutracêutico e para alimentos funcionais. Outro importante desdobramento desta utilização é o reaproveitamento da casca de manga, um dos mais fartos resíduos produzidos durante o processamento da fruta e que, se não utilizado adequadamente, acaba contribuindo para a poluição ambiental. Somado a isso, Ajila e Prasada $\operatorname{Rao}^{87}$ avaliaram a proteção do extrato da casca de manga contra o estresse redox induzido pelo peróxido de hidrogênio em eritrócitos de ratos.

Okonogi e colaboradores ${ }^{89}$ avaliaram a capacidade antioxidante e a citotoxicidade de resíduos de cascas de diferentes frutas: Punica granatum (romã), Nephelium lappaceum (rambutam) e Garcinia mangostana (mangostão), que poderiam ser aproveitados devido ao grande potencial antioxidante.

Alternativas economicamente vantajosas, por meio da exploração completa do conteúdo antioxidante de resíduos de frutas tropicais de fábricas de sucos, foram estudadas. Assim, extratos metanólicos de farinhas de resíduos de acerola, maracujá e abacaxi foram avaliados quanto à sua capacidade antioxidante. Para isso, foram analisados o conteúdo total de fenóis, a capacidade antioxidante frente aos radicais $\mathrm{DPPH}^{*}$ e ânion radical superóxido, e o efeito de proteção à peroxidação da membrana lipídica, causada pelo radical peroxila dos extratos metanólicos das farinhas. Nesta última análise, um modelo de membrana bilamelar fosfolipídica com uma sonda fluorescente foi usado.

Os resultados para o conteúdo total de fenóis dos extratos metanólicos das farinhas de resíduos de acerola, maracujá e abacaxi foram 94,6 \pm 7,4, 41,2 \pm 4,2 e 9,1 $\pm 1,3 \mathrm{mg}$ de equivalentes de ácido 
Tabela 4. Plantas e temperos como fontes naturais de antioxidantes

\begin{tabular}{|c|c|c|}
\hline Fontes & Principais resultados & Ref. \\
\hline Própolis brasileiro & $\begin{array}{l}\text { Relatou-se grande influência dos flavonoides na atividade antioxidante dos } \\
\text { extratos de própolis estudados. }\end{array}$ & 53 \\
\hline Poléns apícolas do sul do Brasil & $\begin{array}{l}\text { O conteúdo total de fenois, flavonoides e a capacidade antioxidante de extratos } \\
\text { etanólicos de pólens apícolas do Rio Grande do Sul mostraram capacidade } \\
\text { semelhante à do } \alpha \text {-tocoferol e maior do que as de BHT e BHA. Foi obtida } \\
\text { correlação positiva entre o conteúdo total de fenois e de flavonoides, sendo os } \\
\text { produtos majoritários, a rutina e miricetina. }\end{array}$ & 54 \\
\hline Quinze espécies de plantas da Amazônia & $\begin{array}{l}\text { Foi observada elevada correlação entre a capacidade antioxidante dos extratos } \\
\text { destas plantas com o conteúdo total de fenois. }\end{array}$ & 55 \\
\hline Plantas medicinais & $\begin{array}{l}\text { Os extratos Terminalia brasiliensis Camb., Terminalia fagifolia Mart. \& Zucc., } \\
\text { Copernicia cerifera (Miller) H.E. Moore, Cenostigma macrophyllum Tul. var. } \\
\text { acuminata Teles Freire e Qualea grandiflora Mart foram estudados. O extrato } \\
\text { do caule de T. brasiliensis, o mais ativo, com valor de } \mathrm{EC}_{50} \text { de } 27,59 \pm 0,82 \\
\mu \mathrm{g} / \mathrm{mL} \text {, foi comparado à rutina }\left(\mathrm{EC}_{50}=27,80 \pm 1,38\right) \text { e ácido gálico }\left(\mathrm{EC}_{50}=\right. \\
24,27 \pm 0,31) \text {. }\end{array}$ & 56 \\
\hline
\end{tabular}

Bauhinia monandra

Grão de pimenta, orégano, noz-moscada, entre outros

Diferentes tipos de temperos processados

Extratos da planta "nó-de-cachorro" (Hereropteris aphrodisiaca)

Óleos essenciais de espécies de Croton do Brasil

Extratos de alecrim (Rosmarinus officinalis Labiatae)

Extratos de gengibre e alecrim
Extratos em clorofórmio e acetato de etila apresentaram maior atividade antioxidante, atribuída à presença de flavonoides e esteroides.

Muitas das espécies analisadas apresentam alto teor de compostos fenólicos e demonstram boa capacidade antioxidante.

Anis, funcho, manjericão, hortelã, estragão e manjerona foram os temperos que apresentaram elevada capacidade antioxidante de acordo com método baseado em biossensor para detecção de polifenois.

Observou-se elevada proteção antioxidante cerebral de extratos da planta "nó-de-cachorro" (Hereropteris aphrodisiaca), administrados a ratos velhos, comparados a ratos jovens.

Os óleos essenciais de Croton zenhtneri e C. argyrophylloides apresentaram maior atividade antioxidante que o $C$. nepetaefolius.

$\mathrm{O}$ alecrim tem demonstrado efeito sinérgico com o ácido cítrico e com o antioxidante BHA.

Foram obtidos por extração em fluido supercrítico. Atividade antioxidante significativa para gengibre e alecrim, por teste ABTS $\left(350\right.$ and $200 \mathrm{mmol} \mathrm{L}^{-1}$ Trolox/g) e DPPH ${ }^{\bullet}\left(145\right.$ and $80 \mathrm{mmol} \mathrm{L}^{-1}$ Trolox/g), respectivamente. Caracterização dos compostos mais ativos. Potenciais candidatos a substitutos de antioxidantes sintéticos para indústrias alimentares e farmacêuticas.

Óleos essenciais de uma série de plantas da Sugeriu-se que óleos essenciais obtidos de várias plantas e temperos podem ser família Ocimum empregados na quimioprevenção do câncer e como alimentos funcionais.

Extratos de brotos de caju (Anarcadium occidentale)

Foram utilizados os ensaios de Folin-Ciocalteau, de captura de $\mathrm{ABTS}^{+}$, DPPH', de $\mathrm{O}_{2}{ }^{--}, \mathrm{NO}^{*}$ e de habilidade de redução de íons férrico. Extrato metanólico apresentou 7 vezes o conteúdo total de fenois, em relação ao extrato hexânico e em acetato de etila.

Inga edulis
A capacidade antioxidante do extrato e dos polifenois puros foi medida pelo teste ORAC e comparada com o teor em fenólicos totais. O extrato bruto seco apresentou valores de ORAC (11,16 mmol TE per g) e CTP (496,5 mg EAG per g) muito altos. Os compostos identificados foram responsáveis, respectivamente, por 9,53 e $12,10 \%$ dos valores ORAC e de CTP do extrato de folhas de Inga edulis. gálico/g de extrato seco, respectivamente. A farinha de resíduo de acerola mostrou o maior conteúdo de fenóis e capacidade antioxidante frente ao radical DPPH'. A farinha de maracujá mostrou a melhor capacidade antioxidante frente ao ânion radical superóxido. Resposta similar foi observada em farinha de acerola e maracujá, quanto à proteção frente à peroxidação da membrana lipídica. De modo geral, estes dados sugerem que extratos metanólicos de farinhas de acerola e maracujá podem ser úteis como suplementos antioxidantes ou aditivos alimentares, especialmente o extrato de acerola. ${ }^{93}$

A importância do processo de extração na obtenção da capacidade antioxidante de resíduos é evidenciada em patente depositada por Mallikarjunaradhya e colaboradores. ${ }^{94}$

\section{Produtos alimentícios obtidos de resíduos da agroindústria}

A Tabela 7 lista alguns estudos que reportam a capacidade 
Tabela 5. Sementes como fontes naturais de antioxidantes

\begin{tabular}{|c|c|c|}
\hline Fontes & Principais resultados & Ref. \\
\hline Sementes de uva & $\begin{array}{l}\text { Extratos de sementes de uva analisados apresentam bom poder redutor, avaliado } \\
\text { com ferrocianato de potássio. Potencial utilização na preservação de produtos } \\
\text { alimentícios. }\end{array}$ & 67 \\
\hline Sementes de tamarindo & $\begin{array}{l}\text { Todos os extratos analisados apresentaram atividade antioxidante }(64,5-71,1 \%) \\
\text { utilizando o sistema de emulsão que envolve ácido linoleico, maior que a do } \\
\text { padrão BHA. }\end{array}$ & 68 \\
\hline $\begin{array}{l}\text { Sementes de abacate, manga, jaca e } \\
\text { tamarindo }\end{array}$ & $\begin{array}{l}\text { Exibem atividade antioxidante e conteúdo total de fenóis maior do que a } \\
\text { porção comestível das respectivas frutas. Esta contribuição foi sempre maior } \\
\text { que } 70 \% \text {. }\end{array}$ & 69 \\
\hline Produtos derivados da castanha de caju & $\begin{array}{l}\text { Observada correlação significativa }(p<0,05) \text { entre a capacidade antioxidante } \\
\text { e a concentração de alquilfenois nos extratos estudados. }\end{array}$ & 70 \\
\hline Sementes de nozes & Sementes de nozes estudadas apresentam grande potencial antioxidante. & 71 \\
\hline Sementes de feijão-fradinho & $\begin{array}{l}\text { Todos os extratos estudados apresentaram atividade antioxidante }(74,3-84,6 \%) \\
\text { pelo sistema do ácido linoleico, porém, usando o método } \beta \text {-caroteno, os valores } \\
\text { encontrados foram menores do que os padrões BHT, BHA e Trolox. }\end{array}$ & 72 \\
\hline Cacau & $\begin{array}{l}\text { O consumo de chocolate aumenta o fluxo dérmico de sangue e seu nível de } \\
\text { saturação com oxigênio. }\end{array}$ & 73 \\
\hline
\end{tabular}

antioxidante de produtos alimentícios fabricados a partir de resíduos da agroindústria. ${ }^{95-98}$ Por exemplo, o estudo de Chantaro, Devahastin e Chiewchan ${ }^{95}$ que avaliaram a capacidade antioxidante de farinhas produzidas a partir de cascas de cenoura provenientes de uma indústria de alimentos. Benakmoum e colaboradores ${ }^{96}$ enriqueceram azeites de oliva refinado e extravirgem e óleo de girassol com carotenoides provenientes de polpa e casca de tomates. Ajila, Leelavathi e Prasada Rao ${ }^{97}$ avaliaram a capacidade antioxidante e o conteúdo de fibras dietéticas de biscoitos enriquecidos com farinha de casca de manga. Zia-ur-Rehman, Habib e Shah ${ }^{98}$ adicionaram extratos de casca de batata como antioxidante natural em óleos de sementes de soja.

\section{Outras fontes}

A capacidade antioxidante de outras fontes naturais também tem sido investigada (Tabela 8). ${ }^{99-101}$ Recentemente, Ferreira e colaboradores ${ }^{99}$ estudaram o poder redutor de duas espécies de cogumelos do nordeste de Portugal. Há uma profusão de estudos que defendem a proteção antioxidante provida por alguns tipos de dieta adotados por determinadas populações. Esta proteção antioxidante envolveria os sistemas nervoso e cardiovascular, resultando em maior longevidade e redução de cardiopatias e doenças neurodegenerativas.

A capacidade antioxidante da dieta do Mediterrâneo, marcada por uma alimentação rica em frutas, verduras, azeite de oliva, alho e vinho, por exemplo, foi avaliada por muitos pesquisadores, como Saura-Calixto e Goñi. ${ }^{100}$ Nestes estudos, é frequente a estimativa de produtos de Maillard, ${ }^{101}$ que são decorrentes da reação de Schiff e posterior isomerização - portanto, não enzimática - entre açúcares redutores (aldoses) e resíduos de aminoácidos básicos (lisina, arginina) de proteínas em alimentos, após processo de aquecimento em altas temperaturas. ${ }^{102}$

Estes produtos de condensação entre aldeídos derivados de produtos de oxidação avançada de lipídios, açúcares e bases de DNA têm sido utilizados como marcadores de doenças e envelhecimento. ${ }^{103-105}$ São denominados, respectivamente, de AGES (Advanced Glycation End-products) e ALES (Advanced Lipoperoxidation Products). O acúmulo em algumas desordens do metabolismo humano (câncer, diabetes, dieta de Atkins, doença de Alzheimer, envelhecimento etc.) de compostos carbonílicos - aldeídos alifáticos, alquenais, alcadienais, $\alpha$ - e $\beta$-dialdeídos e dicetonas, $\beta$-cetoácidos, $\alpha$-aminocetonas, $\alpha$-hidroxialdeídos e $\alpha$-hidroxicetonas etc - derivados da oxidação aeróbica de carboidratos, lipídios, proteínas, DNA e alguns metabólitos, com subsequente formação de produtos de conjugação com biopolímeros, caracteriza um estado metabólito recentemente denominado "estresse carbonílico". 106

Neste contexto, também merece atenção a atividade antioxidante e antirradicalar da $L$ - carnitina, transportador essencial de ácidos graxos de cadeia longa para a matriz mitocondrial. Na medida em que é fundamental para a produção de ATP, a $L$-carnitina é tema recorrente na área de exercício físico. ${ }^{107,108}$

\section{Constituintes químicos principais, responsáveis pela atividade antioxidante}

Em muitos dos trabalhos relatados, identificou-se o princípio antioxidante principal, como no caso do azeite de oliva, o hidroxitirosol, ${ }^{109}$ ou apenas isolaram-se frações detentoras de atividade antioxidante. Deve-se ressaltar que a atribuição inequívoca de atividade antioxidante biológica, mesmo que in vitro ou ex vivo, a compostos isolados e identificados de um extrato não é tarefa fácil, pois vários fatores têm de ser avaliados. Dentre estes, a ação sinergística dos constituintes supostamente ativos, sua absorção pelo sistema gastrointestinal, possíveis atividades tóxicas colaterais, velocidade de metabolização e excreção, dose-resposta etc. Deve-se, também, considerar a necessidade de identificar marcadores de um extrato que atestem a reprodutibilidade de sua preparação e atividade, uma vez que a composição química de qualquer espécie varia segundo muitos fatores: variedade da planta, local de cultivo, estação e hora de coleta, características da entomofauna etc.

Outro problema a ser considerado é relacionado à presença de heterosídeos, de modo geral na forma de $\beta$-glicosídeos. Eles são dificilmente computados no conteúdo total de fenóis, uma vez que não são facilmente extraídos pelos solventes usuais, como acontece com os fenóis livres. No sistema gastrointestinal humano, os alimentos são digeridos no estômago (ambiente ácido, com enzimas), no intestino delgado (ambiente básico, com enzimas) e no cólon ( $\mathrm{pH}$ neutro, presença de microflora intestinal). Os heterosídeos fenólicos não são 
Tabela 6. Resíduos como fontes naturais de antioxidantes

\begin{tabular}{|c|c|c|}
\hline Fontes & Principais resultados & Ref. \\
\hline Resíduos da vinicultura & $\begin{array}{l}\text { O extrato etanólico dos resíduos estudados exibiu elevada atividade antioxidante, } \\
\text { quando comparado com os extratos em outros solventes, contra o antioxidante } \\
\text { sintético BHT, o palmitato de ascorbila e a vitamina E. Não foi observada cor- } \\
\text { relação positiva entre atividade antioxidante e conteúdo total de fenois. }\end{array}$ & 74 \\
\hline Resíduos sólidos de azeitona & $\begin{array}{l}\text { O extrato }(1-20 \mu \mathrm{g} / \mathrm{mL}) \text { analisado foi pré-incubado em células endoteliais e } \\
\text { preveniu a peroxidação lipídica e a morte celular. Os resultados indicam uma } \\
\text { grande capacidade antioxidante dos extratos estudados. }\end{array}$ & 75 \\
\hline Resíduos de carambola & $\begin{array}{l}\text { A alta quantidade de fenois e a elevada capacidade antioxidante dos resíduos } \\
\text { estudados indicam que poderiam ser empregados como aditivos alimentares. }\end{array}$ & 76 \\
\hline Bagaço de uva & $\begin{array}{l}\text { Encontraram-se } 17 \text { tipos de compostos polifenólicos diferentes, entre eles, } \\
\text { ácido gálico, catequina, epicatequina, quercetina. }\end{array}$ & 77 \\
\hline Bagaço de maçã & $\begin{array}{l}\text { Todos os compostos antioxidantes encontrados apresentaram elevada atividade } \\
\text { antioxidante, sendo a atividade sequestradora de radicais DPPH } 2 \text { a } 3 \text { vezes } \\
\text { e a do anion radical superóxido } 10 \text { a } 30 \text { vezes maior do que a das vitaminas } \\
\text { C e E. }\end{array}$ & 78 \\
\hline Resíduos de maçã, pêra e alcachofra & $\begin{array}{l}\text { Foram encontrados extratos com elevado conteúdo de fenois e elevada capaci- } \\
\text { dade antioxidante. }\end{array}$ & 79 \\
\hline Folhas de chá velho e resíduos de chá preto & $\begin{array}{l}\text { O resíduo de chá preto apresentou maior capacidade antioxidante quando } \\
\text { comparado com a folha de chá velho. Recomendam o uso destes chás como } \\
\text { fontes naturais de antioxidantes. }\end{array}$ & 80 \\
\hline Sementes (soja) e resíduos agrícolas de soja & $\begin{array}{l}\text { Os extratos das sementes mostraram variações no conteúdo de fenois }(6,4 \text { a } \\
81,7 \mathrm{mg} \text { EAG/g), de flavonoides ( } 3,5 \text { a } 44,6 \mathrm{mg} \text { QE (quercetina)/g) e atividade } \\
\text { antioxidante }(7,5 \mathrm{a} 74,7 \%) \text {. }\end{array}$ & 81 \\
\hline Resíduos de sementes de groselha preta & $\begin{array}{l}\text { Fenois e os tocoferois foram os mais importantes constituintes do resíduo } \\
\text { pressionado de semente de groselha preta estudado. }\end{array}$ & 82 \\
\hline $\begin{array}{l}\text { Sementes, casca de semente, casca e } \\
\text { óleo de abóbora }\end{array}$ & $\begin{array}{l}\text { O ácido } p \text {-hidroxibenzoico foi o composto fenólico mais abundante nas } \\
\text { amostras estudadas. }\end{array}$ & 83 \\
\hline Resíduos de cebola & $\begin{array}{l}\text { Resíduos de cebola mostraram ser fonte de antioxidantes e de compostos anti- } \\
\text { escurecimento, podendo ser utilizados como ingredientes de alimentos. }\end{array}$ & 84 \\
\hline Casca de maçã & $\begin{array}{l}\text { A preservação dos compostos antioxidantes variou de acordo com o tempo } \\
\text { de estocagem. No período de } 45 \text { dias ocorreu um aumento na quantidade de } \\
\text { antioxidantes. Na estocagem durante } 90 \text { dias, a quantidade de antioxidantes foi } \\
\text { mais preservada em atmosfera controlada quando comparado com estocagem } \\
\text { comum a frio. }\end{array}$ & 85 \\
\hline Casca de manga & $\begin{array}{l}\text { O extrato da casca de manga mostrou atividade antioxidante em diferentes } \\
\text { sistemas e poderia ser usado como nutracêutico e alimento funcional. O ex- } \\
\text { trato da casca de manga mostrou proteção contra modificações morfológicas } \\
\text { e degradação da membrana proteica causada pelo peróxido de hidrogênio. Os } \\
\text { resultados demonstram que o extrato estudado protege os eritrócitos contra o } \\
\text { estresse oxidativo e poderia trazer benefícios à saúde. }\end{array}$ & 86,87 \\
\hline Casca de manga & $\begin{array}{l}\text { A casca de manga apresenta grande potencial como fonte de compostos bené- } \\
\text { ficos para a saúde, fonte de quercetina 3-O glicosilada e mangiferina. }\end{array}$ & 88 \\
\hline Cascas de oito diferentes frutas & $\begin{array}{l}\text { As cascas de rambutan podem ser consideradas uma fonte natural de antioxi- } \\
\text { dantes para alimentação ou ser adicionadas a produtos farmacêuticos, devido } \\
\text { a sua elevada capacidade antioxidante e propriedade não tóxica em células } \\
\text { normais. }\end{array}$ & 89 \\
\hline Resíduos de limão & $\begin{array}{l}\text { Encontrou-se correlação entre teor de compostos fenólicos e a atividade an- } \\
\text { tioxidante total, sendo que tais compostos foram os antioxidantes que mais } \\
\text { contribuíram para a atividade do produto. }\end{array}$ & 90 \\
\hline Bagaço e pedúnculo do caju & $\begin{array}{l}\text { Nas frações estudadas, foram identificados os ácidos gálico, ferúlico, cafeico, } \\
\text { protocatecúico, quínico, cinâmico, gentíssico, } p \text {-cumárico e salicílico, os quais } \\
\text { conferem o potencial antioxidante. Estes resultados caracterizaram in vitro } \\
\text { o potencial antioxidante do bagaço e do extrato bruto do pedúnculo de caju } \\
\text { clone CCP-76. }\end{array}$ & 91 \\
\hline Casca de batata & $\begin{array}{l}\text { Extrato da casca de batata foi capaz de proteger eritrócitos contra o estresse } \\
\text { oxidativo, provavelmente por atuar como potente antioxidante. }\end{array}$ & 92 \\
\hline $\begin{array}{l}\text { Farinhas de resíduos de acerola, maracujá e } \\
\text { abacaxi }\end{array}$ & $\begin{array}{l}\text { Os extratos metanólicos de farinhas de resíduos de acerola (FRAC), maracujá } \\
\text { (FRMA) e abacaxi (FRAB) exibem capacidade antioxidante. FRAC e FRMA } \\
\text { podem ser úteis como suplementos antioxidantes ou aditivos alimentares, em } \\
\text { especial, o extrato de acerola. }\end{array}$ & 93 \\
\hline
\end{tabular}


Tabela 7. Alimentos produzidos a partir de resíduos da agroindústria como fonte de antioxidantes

\begin{tabular}{lll}
\hline Fontes & Principais resultados \\
\hline $\begin{array}{l}\text { Barras de cereais à base de cascas de ce- } \\
\text { noura }\end{array}$ & $\begin{array}{l}\text { O tratamento térmico, durante o branqueamento e secagem, causou diminuição } \\
\text { no conteúdo de } \beta \text {-caroteno e compostos fenólicos, diminuindo a atividade } \\
\text { antioxidante do produto final. }\end{array}$ \\
\hline $\begin{array}{l}\text { Óleos e azeites enriquecidos com carote- } \\
\text { noides }\end{array}$ & $\begin{array}{l}\text { A incorporação da casca do tomate provocou um aumento na concentração } \\
\text { de } \beta \text {-caroteno e licopeno quando comparado com a polpa do tomate puro. }\end{array}$ \\
& $\begin{array}{l}\text { Entretanto, a incorporação do tomate completo (polpa e casca) induziu mel- } \\
\text { hor estabilidade térmica dos óleos refinados quando comparados com o óleo } \\
\text { extravirgem e óleo de girassol. }\end{array}$ \\
\hline $\begin{array}{l}\text { Biscoitos enriquecidos com casca de manga } \\
\text { O conteúdo de polifenois aumentou de 0,54 para 4,50 mg/g e o de carotenoide } \\
\text { de } 17 \text { para 247 } \mu \text { g/g de biscoito com 20\% de adição de farinha de casca de } \\
\text { manga. Biscoitos com boa aceitabilidade foram obtidos após adição de 10\% } \\
\text { de farinha de casca de manga. }\end{array}$ \\
$\begin{array}{ll}\text { Extrato de casca de batata mostrou elevada capacidade antioxidante, igualando- } \\
\text { Se à dos padrões BHA e BHT. Portanto, esse extrato poderia ser utilizado como } \\
\text { batata }\end{array}$ \\
$\begin{array}{l}\text { antioxidante natural, podendo ser adicionado em óleos, gorduras ou outros } \\
\text { produtos alimentícios. }\end{array}$ \\
\hline
\end{tabular}

Tabela 8. Outras fontes naturais de antioxidantes

\begin{tabular}{ll}
\hline Fontes & Principais resultados \\
\hline Cogumelos & $\begin{array}{l}\text { As duas espécies estudadas (Lactarius deliciosus (L) Gray e Tricholoma } \\
\text { portentosum (Fr.)) apresentaram potencial antioxidante, mas a L. deliciosus } \\
\text { mostrou-se mais ativa. }\end{array}$ \\
\hline Dieta do Mediterrâneo & $\begin{array}{l}\text { Uma quantidade de vitaminas C E Eque corresponde a 10\% das recomendações } \\
\text { diárias de consumo foi encontrada. O conteúdo total de fenóis foi estimado em }\end{array}$ \\
& 1171 mg EAG/pessoa/ dia. \\
\hline Extratos voláteis de produtos da reação de & $\begin{array}{l}\text { A atividade antioxidante de cada composto presente no extrato analisado não } \\
\text { foi elevada. O alto poder antioxidante mostrado pelo extrato foi decorrente da }\end{array}$ \\
\hline Maillard & ação sinérgica destes compostos da reação de Maillard. \\
\hline$L$-carnitina & A L-carnitina apresentou alta atividade antioxidante frente aos radicais livres \\
& DPPH', ânion radical superóxido e peróxido de hidrogênio. \\
\hline
\end{tabular}

digeridos no estômago e no intestino delgado, chegando intactos ao cólon, onde são liberados, por hidrólise básica e exibem bioatividades, com benefícios à saúde. Como exemplos, podem ser citados o abacaxi e a banana, que apresentam uma alta proporção de heterosídeos e são digeridos pela flora intestinal. ${ }^{110}$ É interessante ressaltar que, na medicina chinesa, a banana é usada contra contispação intestinal e esse efeito terapêutico pode ser devido à alta percentagem destes constituintes. ${ }^{109}$ Há, portanto, necessidade de atenção na preparação de produtos antioxidantes, pois processos adicionais de digestão com base e extração em fase sólida podem se fazer necessários. ${ }^{110,111}$

\section{MÉTODOS EMPREGADOS NA DETERMINAÇÃO DA CAPACIDADE ANTIOXIDANTE}

A eficiência antioxidante de compostos bioativos em alimentos de origem vegetal depende de sua estrutura e da sua concentração no alimento. Por sua vez, a quantidade destas substâncias em vegetais é amplamente influenciada por fatores genéticos e condições ambientais, além do grau de maturação e variedade da planta, entre outros aspectos. Sabe-se, ainda, que a capacidade antioxidante é influenciada pelo substrato utilizado no ensaio, pelo solvente e pela técnica de extração utilizada, bem como pelo binômio tempo-temperatura. No que se refere aos solventes orgânicos, o metanol, por conseguir extrair elevada quantidade de compostos bioativos, tem sido apontado como o mais efetivo. ${ }^{32,112}$
Em decorrência da grande diversidade química existente, em especial entre os compostos fenólicos, vários ensaios têm sido desenvolvidos para avaliação da capacidade antioxidante de amostras. Alguns deles determinam a habilidade dos antioxidantes em sequestrar espécies reativas geradas no meio reacional. Outros avaliam a eficiência dos antioxidantes em inibir a peroxidação lipídica por meio de: quantificação dos produtos da reação - dienos conjugados e hidroperóxidos; quantificação dos produtos da decomposição da peroxidação lipídica, ou medição da inibição da oxidação do lipídio do sistema pelo antioxidante a ser testado.

Estes ensaios diferem em relação ao mecanismo de reação, às espécies-alvo, às condições reacionais e na forma com os resultados são expressos. Não obstante a diversidade de métodos para avaliar a capacidade antioxidante, não existe um procedimento metodológico universal..$^{7,113,114}$ Este fato impõe a necessidade de avaliar a capacidade antioxidante por diferentes ensaios, com fundamentos e mecanismos de ação diferentes.

De antemão, é necessário frisar que a comparação da capacidade antioxidante entre os diferentes métodos não é feita em valores absolutos, pois cada método tem sua própria escala de valores. Uma padronização é urgentemente requerida e deve seguir os critérios estabelecidos por Huang e Prior: ${ }^{113}$ utilizar moléculas biologicamente relevantes; ser tecnicamente simples; com ponto final e mecanismo químico bem definidos; com instrumentação facilmente disponível; ter boa repetibilidade e reprodutibilidade; ser adaptável para ensaios 
de antioxidantes hidrofílicos e lipofílicos e, para high-throughput análises.

Várias revisões da literatura referem-se a ensaios antioxidantes, 23,113,115 em diferentes matrizes, com avaliação comparativa e crítica entre eles. Um dos mais atuais e abrangentes artigos foi publicado recentemente ${ }^{116} \mathrm{e}$ os princípios químicos dos métodos baseados em oxidantes biológicos ou em ensaios não biológicos são ali listados e discutidos criticamente.

Alguns autores defendem o estudo da capacidade antioxidante total, em vez da análise de antioxidantes isolados, uma vez que há dificuldade em medir cada antioxidante e, principalmente, devido à interação que existe entre eles. Nesta técnica, leva-se em conta a ação acumulativa de todos os antioxidantes presentes; obtém-se, assim, um parâmetro integrado, capaz de revelar nuanças acerca do delicado equilíbrio redox existente in vivo. ${ }^{3}$ No entanto, em artigo recente, Sies ${ }^{116}$ questiona o conceito de "capacidade antioxidante total" avaliada em plasma humano, alegando que sua defesa antioxidante principal são as enzimas. Ele alega que produtos fitoquímicos dietários sofrem diferentes processos de absorção e metabolização e, por isso, uma extrapolação de seus efeitos para a saúde humana requer conhecer, a nível molecular, como o composto atua, ou seja, os efeitos de um composto não podem ser avaliados por um parâmetro genérico como a capacidade antioxidante total.

Os métodos disponíveis para medida de atividade antioxidante são vários e não serão todos aqui apontados, pois há muitas revisões recentes referentes a este tema. ${ }^{3,113,115,117}$ Tampouco serão aqui abordados os métodos de avaliação de atividade antioxidante frente ao oxigênio excitado ao estado singlete $\left({ }^{1} \mathrm{O}_{2}{ }^{*}\right)$, uma espécie menos frequente em sistemas descritos de estresse redox, embora tenha papel reconhecido na lipoperoxidação e na fagocitose. ${ }^{1}$ Sua determinação por método físico exige fotômetros de alta sensibilidade no vermelho e infravermelho próximo, não disponíveis na maioria dos laboratórios; sua dosagem por via química requer sondas doadoras e aceptoras de oxigênio singlete solúveis em água (derivados naftalênicos e antracênicos), muitas delas não disponíveis comercialmente. Serão descritos os métodos mais utilizados, vantajosos pela sua simplicidade metodológica, tempo de análise, custo e relativa especificidade, sendo cada um deles direcionado a um mecanismo antioxidante particular. São métodos que utilizam equipamentos disponíveis na maioria dos laboratórios de pesquisa em Química, Bioquímica e Farmácia e em laboratórios de análises clínicas e indústrias.

\section{Conteúdo total de fenóis}

\section{Método de Folin-Ciocaulteau}

Compostos polifenólicos são importantes constituintes dietéticos, em virtude da sua elevada capacidade antioxidante, atribuída à sua habilidade em complexar íons metálicos, inativar reações radicalares em sistemas deslipidados, e prevenir conversão de hidroperóxido em oxirradicais reativos. ${ }^{118}$

A quantificação de compostos fenólicos é realizada por meio de uma variedade de métodos; todavia, o que utiliza o reagente de FolinCiocalteau (RFC) é o mais extensivamente empregado. ${ }^{19-122}$

O RFC consiste de mistura dos ácidos fosfomolibídico e fosfotungstico, na qual o molibdênio se encontra no estado de oxidação (VI) (cor amarela no complexo $\mathrm{Na}_{2} \mathrm{MoO}_{4} \cdot 2 \mathrm{H}_{2} \mathrm{O}$ ); porém, em presença de certos agentes redutores, como os compostos fenólicos, formam-se os chamados complexos molibdênio-tungstênio azuis [ $\left.\left(\mathrm{PMoW}_{11} \mathrm{O}_{4}\right)^{4-}\right]$, nos quais a média do estado de oxidação dos metais está entre $5(\mathrm{~V})$ e 6 (VI) e cuja coloração permite a determinação da concentração das substâncias redutoras que, não necessariamente, precisam ter natureza fenólica. ${ }^{113,123}$

A Figura 1 mostra a desprotonação dos compostos fenólicos (no exemplo, o padrão ácido gálico) em meio básico, gerando os ânions fenolatos. A partir daí, ocorre uma reação de oxirredução entre o ânion fenolato e o reagente de Folin, na qual, segundo Singleton, Orthofer e Lamuela-Raventós, ${ }^{123}$ o molibdênio, componente do reagente de Folin, sofre redução e o meio reacional muda de coloração amarela para azul.<smiles></smiles>

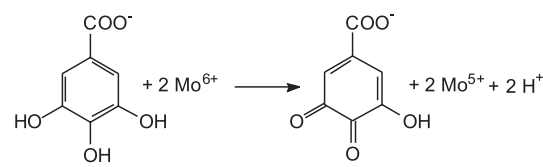

Figura 1. Reação do ácido gálico com molibdênio, componente do reagente de Folin-Ciocaulteau

Na realidade, o RFC, popularmente reconhecido como o teste para medir o conteúdo total de fenois, mede a capacidade redutora das amostras, mas isto não é expresso no nome. Outro ponto fraco do método é que ocorre superestimação do conteúdo fenólico, em larga extensão. ${ }^{93,124}$ Vários interferentes não fenólicos são conhecidos, entre eles, a vitamina C. Em trabalho recente, ${ }^{93}$ foi verificado que a adição de ácido ascórbico a ácido gálico em diferentes proporções $(0,1: 1,0 ; 0,5: 1,0 ; 1,0: 1,0 ; 2,0: 1,0)$ provocou o aumento de absorbância, revelando interferência de cerca de $20 \%$, mas, somente quando a razão ascorbato/galato $\geq 1$. Por outro lado, em vista de processos de extração não eficientes, heterosídeos (éteres ou ésteres) podem não ser avaliados, levando a valores subestimados de conteúdo total de fenóis. ${ }^{109}$ Em vista disto, recomenda-se a determinação de ácido ascórbico e outros possíveis interferentes e a análise das frações insolúveis dos vários extratos, após etapa de digestão básica. ${ }^{109,110}$

\section{Capacidade antioxidante}

\section{Frente ao radical $\mathrm{DPPH}$}

Um dos métodos mais usados para verificar a capacidade antioxidante consiste em avaliar a atividade sequestradora do radical 2,2-difenil-1-picril-hidrazila (DPPH'), de coloração púrpura, que absorve em um comprimento de onda de $516 \mathrm{~nm}$. Por ação de um antioxidante ou uma espécie radicalar $\left(\mathrm{R}^{\circ}\right)$, o $\mathrm{DPPH} \mathrm{H}^{\circ}$ é reduzido formando 2,2-difenilpicril-hidrazina (DPPH-H) (Figura 2), de coloração amarela, com consequente desaparecimento da banda de absorção, sendo a mesma monitorada pelo decréscimo da absorbância. A partir dos resultados obtidos, determina-se a porcentagem de atividade antioxidante (quantidade de $\mathrm{DPPH}^{\circ}$ consumida pelo antioxidante) ou sequestradora de radicais e/ou a porcentagem de $\mathrm{DPPH}^{\circ}$ remanescente no meio reacional. ${ }^{113}$<smiles>C=C=C(NC1C(C)CC([N+](=O)[O-])=CC1[N+](=O)[O-])N(c1ccccc1)C1CC=CCC1</smiles>

Figura 2. Reação química entre o BHT e o radical DPPH

O mecanismo de reação é baseado em transferência de elétrons, enquanto a abstração de átomo de hidrogênio é uma reação marginal, pois a mesma acontece lentamente em solventes que estabelecem 


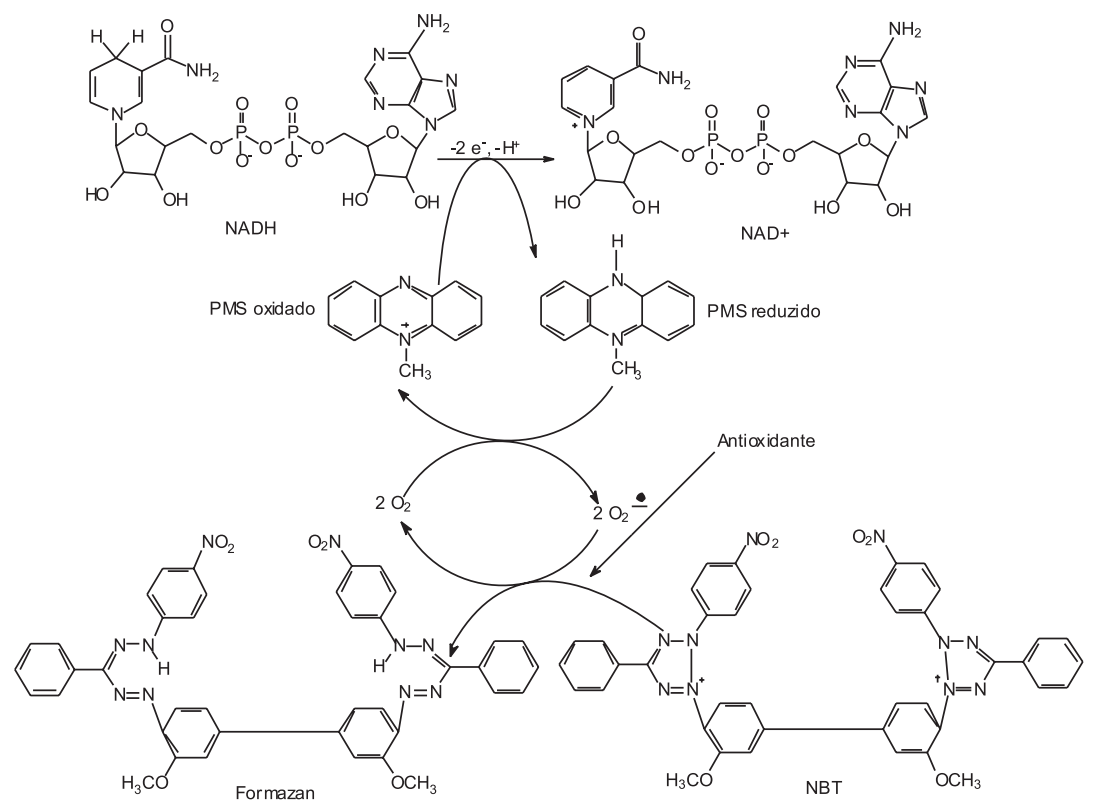

Figura 3. Representação esquemática da geração do ânion radical superóxido e ação de um antioxidante presente no meio. NBT = azul de nitrotetrazólio; PMS: fenazina metassulfato; $N A D H=$ nicotinamida adenina dinucleotídio

fortes ligações de hidrogênio. O método é influenciado pelo solvente e pelo $\mathrm{pH}$ das reações. O método é considerado fácil e útil para análise de substâncias puras e amostras complexas.

\section{Frente ao ânion radical superóxido}

A enzima antioxidante superóxido dismutase catalisa a aniquilação do ânion radical superóxido em peróxido de hidrogênio e água. ${ }^{125}$ Técnicas que utilizam a superóxido dismutase não são simples e, além disso, apresentam custo elevado relativo à enzima padrão. Diante disto, Ewing e Janero ${ }^{126}$ desenvolveram um método enzimático indireto de geração de superóxido em microplacas, que se mostra rápido e econômico. A reação que ocorre nesse método está representada na Figura 3. Esta reação tem início com a adição de NADH (nicotinamida adenina dinucleotídeo) à mistura de PMS (fenazina metassulfato) e NBT (azul de nitrotetrazólio), com formação do ânion radical superóxido. Em seguida, dois radicais superóxido são capazes de doar, cada um, um elétron para o NBT, que se reduz a formazana, então monitorada em um comprimento de onda de 560 $\mathrm{nm}$, em espectrofotômetro UV-Vis. Quando algum antioxidante é adicionado no meio, ele é capaz de competir com o NBT pelo ânion radical superóxido gerado, diminuindo, dessa forma, a redução do NBT e, consequentemente, a formação de formazana.

\section{Inibição da lipoperoxidação}

Um bom antioxidante "químico" pode ser um antioxidante "biológico" menos eficaz. Em função disso, muitos pesquisadores utilizam métodos de avaliação in vitro, na presença de lipossomos sintéticos simuladores das membranas biológicas. ${ }^{127}$ Técnicas fluorimétricas são frequentemente utilizadas na medida da lipoperoxidação. O método fundamenta-se no decaimento da fluorescência emitida por uma sonda acoplada ao lipossomo, através do ataque de uma espécie reativa. Após a adição de uma espécie redutora, ou seja, o antioxidante, observa-se um menor decaimento da fluorescência. Isto significa que a membrana foi protegida e o antioxidante foi atacado pelas espécies reativas presentes no meio. ${ }^{128}$

Todos os componentes celulares são suscetíveis à ação das espécies reativas de oxigênio. Entretanto, a membrana é um dos componentes mais atingidos, o que acarreta alterações na sua estrutura e na sua permeabilidade. Consequentemente, há perda da seletividade na troca iônica e liberação do conteúdo de organelas, como as enzimas hidrolíticas dos lisossomas, e formação de produtos citotóxicos (como o malonaldeído), culminando com a morte celular. A lipoperoxidação também pode estar associada aos mecanismos de envelhecimento, de câncer e à exacerbação da toxicidade de xenobióticos. ${ }^{10}$

\section{Sistema hipoxantina/xantina oxidase (HX/XO) usado na dosagem de radical hidroxila}

A metodologia desenvolvida por Owen e colaboradores ${ }^{129-131}$ consiste em um sistema enzimático contendo a hipoxantina como substrato e uma enzima, a xantina oxidase (Figura 4). Esta enzima catalisa a oxidação de hipoxantina a xantina, a qual é, então, oxidada a ácido úrico. Em ambas as etapas da oxidação da hipoxantina a ácido úrico, há produção de ânion radical superóxido, que reduz FeIII a FeII, cuja reação com $\mathrm{H}_{2} \mathrm{O}_{2}$ gera radical hidroxila (reação de HaberWeiss catalisada por ferro). Este radical reage com o ácido salicílico, presente no meio, formando os ácidos benzoicos di-hidroxilados [ácido 2,3-di-hidroxibenzoico (2,3-DHBA) e ácido 2,5-di-hidroxibenzoico (2,5-DHBA)]. A hipoxantina e o ácido salicílico, incluindo os produtos de oxidação de ambos, são previamente quantificados por um experimento padrão utilizando cromatografia líquida de alta eficiência. Portanto, é possível adicionar ao sistema uma amostra que tenha capacidade antioxidante para ser avaliada. Assim, se a referida amostra conseguir competir com o ácido salicílico na captura dos radicais hidroxila, menores quantidades de 2,3-DHBA e 2,5-DHBA serão formadas, indicando então a capacidade antioxidante para a amostra analisada. Se ocorrer diminuição da concentração de ácido úrico, significará que houve a inibição da enzima xantina oxidase, fonte indireta de radical hidroxila.

\section{ANTIOXIDANTES NA ÁREA NUTRICIONAL}

$\mathrm{O}$ interesse crescente no emprego de nutrientes antioxidantes visando, por exemplo, a melhoria geral da saúde e o retardo no processo de envelhecimento tem atraído a atenção da população em geral, que deseja saber quais são os benefícios da ingestão de suple- 


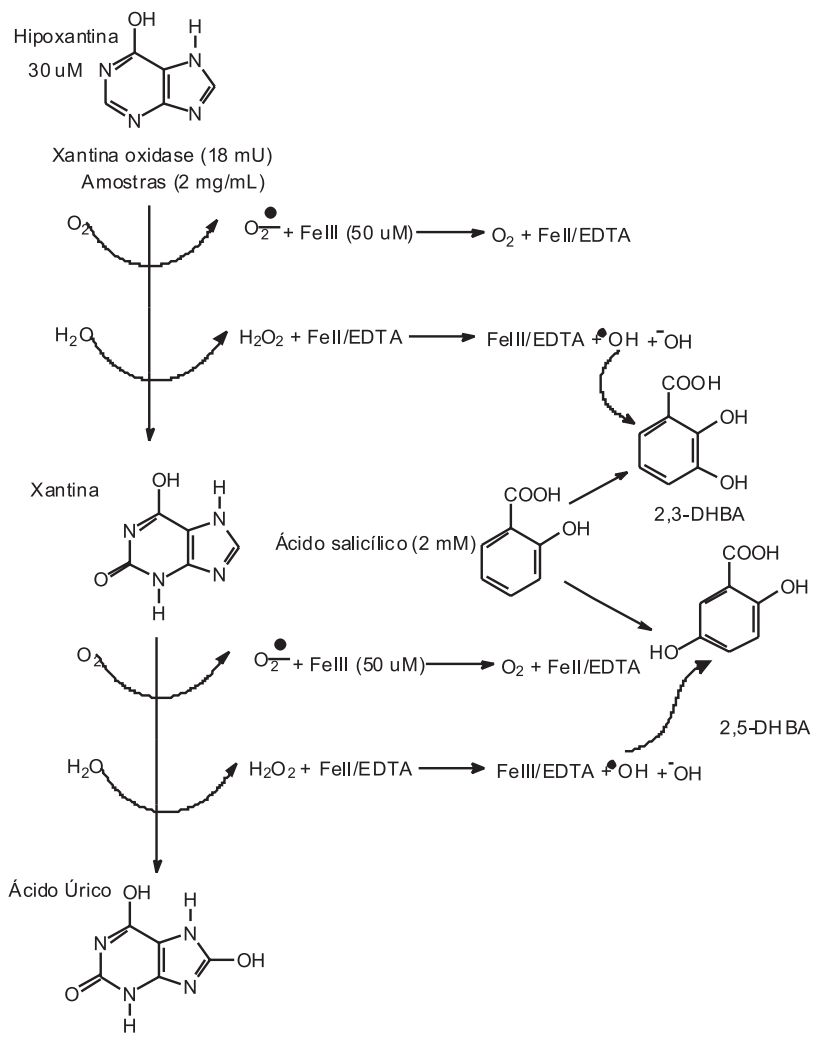

Figura 4. Esquema representativo do ensaio antioxidante hipoxantinal xantina oxidase

mentos antioxidantes. Vários estudos na literatura descrevem o uso de suplementos antioxidantes no tratamento de diversas patologias: alguns deles, com atividade direta sobre espécies reativas, e outros como quelantes de metais indutores de estresse oxidativo, como o Succimer $^{\circledR}$ (2,3-dimercaptosuccinatos) e orto-difenóis. ${ }^{9,30,132-134}$

Quanto ao uso de vitaminas antioxidantes, há um vasto e controverso campo de descobertas. As vitaminas $\mathrm{C}, \mathrm{E}$ e o $\beta$-caroteno têm sido apontados como atuantes na prevenção de doenças crônicas, em especial doenças cardiovasculares (DCV) e câncer. ${ }^{135,136}$ Porém, a literatura nessa área se destaca por resultados controversos em experimentos semelhantes; talvez, em alguns casos, a urgência em obter resultados positivos comprometa o necessário rigor científico das investigações. ${ }^{137}$

Embora haja muitos trabalhos assegurando a atividade antioxidante da vitamina $\mathrm{E}$, in vitro e in vivo, $\mathrm{Azzi}^{13}$ alerta para alguns fatos: muitos antioxidantes não são capazes de substituir o $\alpha$-tocoferol (Vit. E) em várias reações celulares; não existe resposta de expressão gênica compensatória à deficiência de Vit. E; a absorção de Vit. E pelo sistema gastrointestinal é muito singular; o processo de degradação oxidativa desta vitamina é lento e, há diferenças biofuncionais importantes entre os vários tocoferois e tocotrienois não relacionáveis as suas estrutura e atividade. $\mathrm{O}$ autor, por meio desta lista, argumenta fortemente a favor de um papel não-antioxidante desta vitamina, possivelmente naquele de interferir nas vias de sinalização celular. Por outro lado, deve-se considerar que o próprio sistema enzimático antioxidante de um organismo pode responder majoritariamente pela sua proteção contra espécies reativas, dando pouco espaço para a atuação suplementar de vitaminas administradas.

Dentre todas as doenças em que o estresse oxidativo causa complicações, as doenças cardiovasculares são as que contam com maiores evidências. Supõe-se que as vitaminas E e o $\beta$-caroteno possam inibir a oxidação das LDLs (low-density lipoprotein ou lipoproteínas de baixa densidade) para a sua forma mais aterogênica e, assim, preservar o endotélio. ${ }^{135}$ Contudo, faltam estudos conclusivos que substanciem a noção de que consumindo mais vitamina $C$, vitamina $E$ ou $\beta$-caroteno (ou outros carotenoides) se reduza o risco destas doenças.

A avaliação segura de terapia antioxidante não é absolutamente trivial em vista destas considerações e pelo fato de uma atividade antioxidante verificada in vitro com sistemas-modelo ser incapaz de mimetizar a realidade da célula, com suas especificidades: vários compartimentos, membranas com permeabilidade seletiva, concentrações diferentes de espécies reativas e alvos moleculares e microambientes com diferentes $\mathrm{pHs}$, polaridades, capacidade de solubilizar peróxidos $\left(\mathrm{H}_{2} \mathrm{O}_{2}, \mathrm{ROOH}, \mathrm{HOONO}\right)$ e gases $\left(\mathrm{NO}\right.$ e $\left.\mathrm{O}_{2}\right) .{ }^{114}$ Ou seja, um bom antioxidante "químico" pode ser um antioxidante "biológico" menos eficaz.

Apesar das controvérsias, para as vitaminas $\mathrm{C}$ e E, foram estabelecidas as recomendações nutricionais diárias considerando a atividade antioxidante além da atividade nutricional - $90 \mathrm{mg}$ para homens e 75 mg para mulheres de vitamina $\mathrm{C}$ e $15 \mathrm{mg}$ para homens e mulheres de vitamina E. ${ }^{138}$ Em relação aos carotenoides, os estudos existentes ainda não foram suficientemente conclusivos para o estabelecimento de recomendações nutricionais, apesar de se saber que tais substâncias influenciam as reações bioquímicas do sistema oxidativo. ${ }^{23,138}$

Para os flavonoides, discute-se, ainda, se os mesmos são nutrientes, uma vez que eles são metabolizados, em grande extensão no organismo, de tal forma a não alcançarem concentração ideal para agirem como antioxidantes. ${ }^{139}$ Isto, porém, não implica em desconsiderar a relevância de tais substâncias na dieta, bem como sua atividade antioxidante. ${ }^{23,138}$ Em trabalho recente, Spencer ${ }^{139}$ atribuiu aos flavonoides importante atividade em processos cerebrais ligados à memória, exercendo efeitos neuroprotetores, devido a interações com macromoléculas responsáveis por caminhos de sinalizações em neurônios, fundamentais para a sobrevivência e diferenciação celulares e para a memória. Há impacto de flavonoides na arquitetura celular do cérebro. Como essa sofre deterioração com a idade, uma dieta rica em flavonoides poderia, eventualmente, reverter o processo de deterioração. Essa área de grande interesse científico necessita estudos adicionais, no entanto, há forte possibilidade de que esses agentes venham a constituir os primeiros candidatos para uma nova geração de fármacos com ação em memória. ${ }^{139}$

De acordo com a American Dietetic Association (Associação Dietética Americana), ${ }^{140}$ a melhor estratégia nutricional para promover a saúde e reduzir o risco de doenças crônicas é a obtenção de nutrientes de uma grande variedade de alimentos. Os suplementos vitamínicos e de minerais só seriam apropriados quando bem aceitos pelo paciente, e prescritos somente após comprovação científica de sua eficácia e segurança.

\section{CONSIDERAÇÕES FINAIS E PERSPECTIVAS}

Nesta revisão, enfatizou-se a possibilidade de muitas plantas - in natura, processadas ou seus resíduos agroindustriais - serem fontes de antioxidantes. Assim, procurou-se estudar frutas, tubérculos, cascas, sementes, óleos, entre outros componentes das plantas, visando verificar o seu potencial antioxidante. Os mais promissores são os produtos de processamento de uvas, acerola e alguns temperos, como gengibre e alecrim. Alguns alimentos (assim como cosméticos) já foram enriquecidos com estes resíduos, com alto grau de sucesso.

O genótipo, ${ }^{37}$ o modo de plantio e fatores ambientais (local, período de coleta, tipo de solo e composição mineral, pós-colheita e os diferentes processamentos) podem afetar a biossíntese dos antioxidantes produzidos, fazendo-se necessária, portanto, uma colaboração multidisciplinar. ${ }^{141}$ Estudos genéticos, para obter uma maior produção de agentes antioxidantes e o desenvolvimento de tecnologias como o nanoencapsulamento, que controlaria a incor- 
poração ou a perda de antioxidantes e vitaminas, ${ }^{142}$ são perspectivas de grande interesse na área.

Antioxidantes naturais, na maioria das vezes, apresentam capacidades antioxidantes menores do que as dos compostos sintéticos, mas a legislação é mais flexível em relação a estes. Em todo caso, é necessário um estudo econômico detalhado, com atenção cuidadosa em relação à toxicidade potencial. Estudos nessa linha devem ser realizados antes da possível aplicação em escala. ${ }^{32} \mathrm{~A}$ discussão de testes toxicológicos e antimicrobianos foge do escopo do presente trabalho, porém os mesmos são fundamentais para a liberação para uso industrial ou artesanal dos vários produtos, em alimentação humana. Soni e colaboradores publicaram uma revisão recente sobre medidas de segurança alimentar em relação ao extrato de polpa de azeitona, ${ }^{109}$ com exemplos também de frutos comestíveis (Punica granatum, romã),${ }^{143}$ que devem ser seguidos.

Em termos experimentais, o processo de extração é uma etapa chave na obtenção de antioxidantes em rendimento aceitável. Para selecionar um solvente, estudos comparativos são necessários para cada substrato. Além das extrações convencionais com etanol, metanol e acetato de etila, outros métodos, como extração em fase supercrítica, são úteis, uma vez que fornecem bons rendimentos e preservam as propriedades antioxidantes. Alguns tratamentos, como digestão básica seguida do adequado tratamento dos resíduos, ${ }^{109,110}$ mostram-se necessários em alguns alimentos, com alta porcentagem de heterosídeos fenólicos insolúveis.

Em termos de avaliação da capacidade antioxidante, existem muitos métodos, com fundamentos, mecanismos de reação e maneiras de expressar resultados muito diferentes. Além do mais, em vista das diversas aplicações (fisiologia, farmacologia, nutrição, agroquímica, cosmética e outras) torna-se difícil escolher os métodos mais apropriados, de modo a evitar a interpretação errônea dos resultados. A comparação de dados a partir de diferentes estudos é também difícil. No momento, é preferível realizar uma bateria de ensaios, com medida de diferentes aspectos químicos dos antioxidantes, compará-los com compostos sintéticos consagrados como antioxidantes - como BHT, Trolox e $N$-acetilcisteína (NAC) - gerando, assim, um perfil antioxidante completo, sem perder de vista a relação com a potencial aplicação do produto. Devem-se escolher métodos comumente aceitos, validados e padronizados, com informações acumuladas na literatura. Esforços têm sido consistentemente envidados, especialmente nos últimos anos, para organizar essa área de pesquisa, ampla e em crescimento exponencial. Outros métodos analíticos in vitro devem ser desenvolvidos, obrigatoriamente levando-se em consideração o uso de oxidantes e alvos de significância biológica (proteínas, triacilglicerois e modelos celulares), em condições reacionais (concentração, tempo de reação, $\mathrm{pH}$ ) as mais próximas possíveis daquelas in vivo (na presença de lipossomos, por exemplo). O uso de dispositivos microfluídicos, a análise em fluxo, a quantificação de várias espécies antioxidantes simultaneamente, a miniaturização, a estabilidade, a portabilidade devem ser também considerados.

Nesse sentido, esta linha de investigação desponta como área de interesse imediato para os mais diversos setores do conhecimento, uma vez que envolve aspectos da química, nutrição, agronomia, biologia, estatística e medicina, entre outras, no sentido de encontrar respostas para promoção da saúde das pessoas e do meio ambiente; portanto, para a melhoria da qualidade de vida. Embora sem a devida comprovação científica da relação direta antioxidante-melhoria das condições de saúde, é prudente e sábio, em termos de saúde pública, aumentar o consumo de alimentos vegetais.

\section{AGRADECIMENTOS}

Aos órgãos financiadores CNPq, CAPES, CNPq/PADCT, PRO-
CAD/NF/CAPES, FAPESP, Projeto do Milênio Redoxoma, Projeto do Milênio Inovação em Fármacos, FAPEAL e ao RENORBIO, pelos auxílios e bolsas concedidos. Agradecem também a inestimável colaboração de M. Z. C. Martins, pela edição do texto em português.

\section{LISTA DE ABREVIATURAS}

ABTS = 2,2-Azinobis-(3-etilbenzotiazolina-6-sulfonato), sal de diamônio

AGES = Advanced Glycation End-products

ALES = Advanced Lipoperoxidation Products

BHA $=$ Hidroxianisol butilado

BHT $=$ Hidroxitolueno butilado

CTP $=$ Conteúdo Total de Fenís

2,3-DHBA = Ácido 2,3-di-hidroxibenzoico

2,5- DHBA = Ácido 2,5-di-hidroxibenzoico

$\mathrm{DPPH}^{*}=$ Radical 2,2-difenil-1-picril-hidrazila

DPPH-H = 2,2-difenilpicril-hidrazina

EAG = Equivalentes de Ácido Gálico

FRAB = Farinha de resíduos de abacaxi

FRAC $=$ Farinha de resíduos de acerola

FRMA = Farinha de resíduos de maracujá

$\mathrm{HX} / \mathrm{XO}=$ Hipoxantina/Xantina Oxidase

NAC $=N$-acetilcisteína

$\mathrm{NADH}=$ Nicotinamida adenina dinucleotídeo

NBT $=$ Azul de nitrotetrazólio

ORAC = Oxygen-Radical Absorbancy Capacity - Capacidade de absorvência do radical oxigênio

PMS $=$ Fenazina metassulfato

RFC $=$ Reagente de Folin-Ciocalteau

TRAP = Total Radical-Trapping Antioxidant Parameter . Parâmetro antioxidante relacionado à captura total de radicais

TROLOX = Ácido 6-hidroxi-2,5,7,8-tetrametilcroman-2-carboxílico

\section{REFERÊNCIAS}

1. Halliwell, B.; Gutteridge, J. M. C.; Free Radicals in Biology and Medicine, $4^{\text {th }}$ ed.; Oxford University Press: Oxford, 2007.

2. Rahman, I.; Biswas, S.; Kode, A.; Eur.J. Pharmacol. 2006, 533, 222.

3. Vasconcelos, S. M. L.; Goulart, M. O. F.; Moura, J. B. F.; Manfredini, V.; Benfato, M. S.; Kubota, L. T.; Quim. Nova 2007, 30, 1323.

4. Finkel, T.; Holbrook, N. J.; Nature 2000, 408, 239.

5. Cilento, G.; Adam, W.; Free Radical Biol. Med. 1995, 19, 103.

6. Velosa, A. C.; Baader, W. J.; Stevani, C. V.; Mano, C. M.; Bechara, E. J. H.; Chem. Res. Toxicol. 2007, 20, 1162.

7. Halliwell, B.; Biochem. Pharmacol. 1995, 49, 1341.

8. Muller, F. L.; Lustgarten, M.; Jang, Y.; Richardson, A.; van Remmen, H.; Free Radical Biol. Med. 2007, 43, 477.

9. Neri, S.; Signorelli, S.; Torrisi, B.; Pulvirenti, D.; Mauceri, B.; Abate, G.; Ignaccolo, L.; Bordonaro, F.; Cilio, D.; Calvagno, S.; Leotta, C.; Clin. Therapeutics 2005, 27, 1764.

10. Niki, E.; Yoshida, Y.; Saito, Y.; Noguchi, N.; Biochem. Biophys. Res. Commun. 2005, 338, 668.

11. Thomas, S.; Balasubramanian, K. A.; Free Radical Biol. Med. 2004, 36, 745.

12. Hansen, J. M.; Go, Y.-M.; Jones, D. P.; Annu. Rev. Pharmacol. Toxicol. 2006, 46, 215.

13. Azzi, A.; Biochem. Biophys. Res. Commun. 2007, 362, 230.

14. Zibadi, S.; Farid, R.; Moriguchi, S.; Lu, Y.; Foo, L.; Tehrani, P.; Ulreich, J.; Watson, R.; Nutr. Res. 2007, 27, 408.

15. John, J. H.; Ziebland, S.; Yudkin, P.; Roe, L. S.; Neil, H. A. W.; The Lancet 2002, 359, 1969. 
16. Gaziano, J. M.; Manson, J.; Branch, L.; Colditz, G.; Willett, W.; Buring, J.; Ann. Epidemiol. 1995, 5, 255.

17. Hartman, R. E.; Shah, A.; Fagan, A.; Schwetye, K.; Parsadanian, M.; Schulman, R.; Finn, M.; Holtzman, D.; Neurobiology of Disease 2006, 24,506 .

18. Gaziano, J. M.; Nutrition 1996, 12, 583.

19. Stanner, S. A.; Hughes, J.; Kelly, C. N. M.; Buttriss, J.; Public Health Nutrition 2004, 7, 407.

20. Cicerale, S.; Conlan, X. A.; Sinclair, A. J.; Keast, R. S.; Crit. Rev. Food Sci. Nutr. 2009, 49, 218.

21. Kim, Y.; Giraud, D. W.; Driskell, J. A.; J. Food Compos. Anal. 2007, 20 458.

22. Zulueta, A.; Esteve, M.; Frasquet, I.; Frígola, A.; Food Chem. 2007, 103, 1365.

23. Vasconcelos, S. M. L.; Silva, A. M.; Goulart, M. O. F.; Nutrire 2006 31,95 .

24. Halliwell, B.; Free Radical Res. Commun. 1990, 9, 1

25. Vendemiale, G.; Grattagliano, I.; Altomare, E.; Int. J. Clin. Lab. Res. 1999, 29, 49.

26. Assunção, N. A.; Bechara, E. J. H.; Simionato, A. V. C.; Tavares, M. F. M.; Carrilho, E.; Quim. Nova 2008, 31, 2124.

27. Mousa, A. S.; Mousa, S. A. Nutr. Res. 2007, 27, 119.

28. Bjelakovic, G.; Nikolova, D.; Simonetti, R. G.; Gluud, C.; J. Hepatol. 2006, 44, S97.

29. Moriarty-Craige, S. E.; Adkison, J.; Lynn, M.; Gensler, G.; Bressler, S.; Jones, D.; Sternberg, P.; Am. J. Ophthalmol. 2005, 140, 1020.

30. Baldwin, C. M.; Bell, I.; Guerra, I.; Quan, S.; Sleep Medicine Rev. 2005 , $9,459$.

31. Dorko, C.; Food Technol. 1994, 48, 33.

32. Moure, A.; Cruz, J.; Franco, D.; Dominguez, J.; Sineiro, J.; Dominguez, H.; Núnez, M.; Parajó, J.; Food Chem. 2001, 72, 145

33. Pantelidis, G. E.; Vasilakakis, M.; Manganaris, G. A.; Diamantidis, G. R.; Food Chem. 2007, 102, 777.

34. Leong, L. P.; Shui, G.; Food Chem. 2002, 76, 69.

35. Kuskoski, E. M.; Asuero, A.; Morales, M.; Fett, R.; Ciência Rural Santa Maria 2006, 36, 1283.

36. Gardner, P. T.; White, T.; Mcphail, D.; Duthie, G.; Food Chem. 2000 $68,471$.

37. Barreto, J. C.; Trevisan, M. T. S.; Hull, W. E.; J. Agric. Food Chem 2008, 56, 5599

38. Ribeiro, S. M. R.; Barbosa, L. C. A.; Queiroz, J. H.; Knödler, M.; Schieber, A.; Food Chem. 2008, 110, 620.

39. Ayala-Zavala, J. F.; Wang, S.; Wang, C.; Gonzalez-Aguila, G.; Lebensm.-Wiss. u.-Technol. 2004, 37, 687.

40. Khalili, F.; Shekarchi, M.; Mostofi, Y.; Pirali-Hamedani, M.; Adib, N.; Faslnamah-i Giyahan-i Daruyi 2008, 7, 53. AN 2008:1152394 CAPLUS.

41. Klimczak, I.; Malecka, M.; Szlachta, M.; Gliszczynska-Swiglo, A.; J. Food Compos. Anal. 2007, 20, 313.

42. Jardini, F. A.; Mancini Filho, J.; Revista Brasileira de Ciências Farmacêuticas 2007, 43.

43. Smail, A.; Marjan, Z. M.; Foong, C. W.; Food Chem. 2004, 87, 581.

44. Liu, X.; Ardo, S.; Bunning, M.; Parry, J.; Zhou, K.; Stushnoff, C.; Stoniker, F.; Yu, L.; Kendall, P.; LWT 2007, 40, 552.

45. Melo, E. A.; Maciel, M.; Lima, V.; Leal, F.; Caetano, A.; Nascimento, R.; Ciência e Tecnologia de Alimentos 2006, 26, 639.

46. Nikfardjem, M. S.; László, G. Y.; Dietrich, H.; Food Chem. 2006, 96, 74.

47. De Beer, D.; Joubert, E.; Gelderblom, W. C. A.; Manley, M.; Food Chem. 2005, 90, 569

48. Alamprese, C.; Pompei, C.; Scaramuzzi, F.; Food Chem. 2005, 90, 495.

49. Ghiselli, A.; Natella, F.; Guidi, A.; Montanari, L.; Fantozzi, P.; Scaccini, C.; J. Nutr. Biochem. 2000, 11, 76.
50. Thiagarajan, G.; Chandani, S.; Sundari, S.; Rao, H.; Kulkarni, A.; Balasubramanian, D.; Exp. Eye Res. 2001, 73, 393.

51. Luczaj, W.; Skrzydlewska, E.; Preventive Medicine 2005, 40, 910.

52. Turkmen, N.; Sari, F.; Velioglu, S.; Food Chem. 2006, 99, 835

53. Silva, J. F.; Souza, M.; Matta, S.; Andrade, M.; Vidal, F.; Food Chem. 2006, 99, 431.

54. Carpes, S. T.; Prado, A.; Moreno, I. A. M.; Mourão, G. B.; de Alencar, S. M.; Masson, M. L.; Quim. Nova 2008, 31, 1660.

55. Silva, E. M.; Souza, J. N. S.; Rogez, H.; Rees, J. F.; Larondelle, Y.; Food Chem. 2007, 101, 1012

56. Sousa, C. M.; Silva, H.; Vieira-Jr, G.; Ayres, M.; Costa, L.; Araújo, D.; Cavalcante, L.; Barros, E.; Araújo, P.; Brandão, M.; Chaves, M.; Quim. Nova 2007, 30, 351.

57. Argolo, A. C. C.; Santana, A. E. G.; Pletsch, M.; Coelho, L. C. B. B.; Bioresour. Technol. 2004, 95, 229.

58. Shan, B.; Cai, Y. Z.; Sun, M.; Corke, H.; J. Agric. Food Chem. 2005, 53, 7749 .

59. Bonanni, A.; Campanella, L.; Gatta, T.; Gregori, E.; Tomassetti, M.; Food Chem. 2007, 102, 751.

60. Mattei, R.; Barros, M. P.; Galvão, S. M. P.; Bechara, E. J. H.; Carlini, E. L. A.; Phytother. Res. 2001, 15, 604.

61. De Morais, S. M.; Catunda Jr., F. E. A.; Da Silva, A. R. A.; Martins Neto, J. S.; Rondina, D.; Cardoso, J. H. L.; Quim. Nova 2006, 29 , 907

62. Medsen, H. L.; Bertelsen, G.; Trends Food Sci. Technol. 1995, 6, 271.

63. Justo, O. R.; Moraes, A. M.; Barreto, G. P. M.; Mercadante, A. Z.; Vieira e Rosa, P. T.; Quim. Nova 2008, 31, 1699.

64. Trevisan, M. T. S.; Silva, M. G. V.; Pfundstein, B.; Spiegelhalder, B.; Owen, R.; J. Agric. Food Chem. 2006, 54, 4378

65. Razali, N.; Razab, R.; Junit S. M.; Aziz, A. A.; Food Chem. 2008, 111, 38.

66. Souza, J. N. S.; Silva, E. M.; da Silva, M. N.; Arruda, M. S. P.; Larondelle, Y.; Rogez H.; J. Braz. Chem. Soc. 2007, 18, 1276.

67. Jayaprakasha, G. K.; Singh, R. P.; Sakariah, K. K.; Food Chem. 2001, $73,285$.

68. Siddhuraju, J.; LWT 2007, 40, 982

69. Soong, Y.; Barlow, P.; Food Chem. 2004, 88, 411.

70. Trevisan, M. T. S.; Spiegelhalder, B.; Bartsch, H.; Owen, R.; Wurtele, G.; Pfundstein, B.; Haubner, R.; Food Chem. Toxicol. 2006, 44, 188.

71. Yang, J.; Liu, R. H.; Halim, L.; LWT 2009, 42, 1

72. Siddhuraju, P.; Becker, K.; Food Chem. 2007, 101, 10.

73. Neukam, K.; Stahl, W.; Tronnier, H.; Sies, H.; Heinrich, U.; Eur. J. Nutr. $\mathbf{2 0 0 7}, 46,53$

74. Lafka, T.; Sinanoglou, V.; Lazos, E. S.; Food Chem. 2007, 104, 1206.

75. Aldini, G.; Piccoli, A.; Beretta, G.; Morazzoni, P.; Riva, A.; Marinello, C.; Maffei Facino, R.; Fitoterapia 2006, 77, 121.

76. Shui, G.; Leong, L. P.; Food Chem. 2006, 97, 277.

77. Lu, Y.; Foo, L. Y.; Food Chem. 1999, 65, 1.

78. Lu, Y.; Foo, L. Y.; Food Chem. 2000, 68, 81.

79. Peschel, W.; Sánchez-Rabaneda, F.; Diekmann, W.; Plescher, A.; Gartzia, I.; Jiménez, D.; Lamuela-Raventos, R.; Buxaderas, S.; Codina, C.; Food Chem. 2006, 97, 137

80. Farhoosh, F.; Golmovahhed, G. A.; Khodaparast, M. H. H.; Food Chem 2007, 100, 231

81. Prakash, D.; Upadhyay, G.; Singh, B.; Singh, H.; Food Chem. 2007, 104, 783.

82. Helbig, D.; Böhm, V.; Wagner, A.; Schubert, R.; Jahreis, G.; Food Chem. 2008, $1,1043$.

83. Pericin, D.; Krimer, V.; Trivic, S.; Radulovic, L.; Food Chem. 2009, 113, 450 .

84. Roldan, E.; Sanchez-Moreno, C.; Ancos, B.; Cano, M. P.; Food Chem. 2008, 108, 907

85. Łata, B.; Scientia Horticulturae 2008, 117, 45 
86. Ajila, C. M.; Naidu, K. A.; Bhat, S. G.; Prasada Rao, U. J. S.; Food Chem. 2007, 105, 982.

87. Ajila, C. M.; Prasada Rao, U. J. S.; Food Chem. Toxicol. 2008, 46, 303.

88. Berardini, N.; Knödler, M.; Schieber, A.; Carle, R.; Food Chem. 2007, $105,982$.

89. Okonogi, S.; Duangrat, C.; Anuchpreeda, S.; Tachakittirungrod, S.; Chowwanapoonpohn, S.; Food Chem. 2007, 103, 839.

90. Kuljarachanan, T.; Devahastin, S.; Chiewchan, N.; Food Chem. 2009, $113,944$.

91. Broinizi, P. R. B.; Andrade-Wartha, E. R. S.; Silva, A. M. O.; Novoa, A. J. V.; Torres, R. P.; Azeredo, H. M. C.; Alves, R. E.; Mancini Filho, J.; Cienc. Tecnol. Aliment. 2007, 27, 902.

92. Singh, J.; Upadhyay, G.; Prasad, A. K. K.; Bahadur, A.; Raí, M.; J. Food Compos. Anal. 2007, 20, 106.

93. De Oliveira, A. C.; Valentim, I. B.; Silva, C. A.; Bechara, E. J. H.; De Barros, M. P.; Mano, C. M.; Goulart, M. O. F.; Food Chem. 2009, 115, 469.

94. Mallikarjunaradhya S.; Kulkarni A. P.; Divakar, S.; WO2004056444-A1; AU2002348732-A1.

95. Chantaro, P.; Devahastin, S.; Chiewchan, N.; LWT 2008, 41, 1987.

96. Benakmoum, A.; Abbeddou, S.; Ammouche, A.; Kefalas, P.; Gerasopoulos, D.; Food Chem. 2008, 110, 684.

97. Ajila, C. M.; Leelavathi, K.; Prasada Rao, U. J. S.; J. Cereal Science 2008, $48,319$.

98. Zia-Ur-Rehman; Habib, F.; Shah, W. H.; Food Chem. 2004, 85, 215.

99. Ferreira, I.C.F.; Baptista, P.; Vilas-Boas, M.; Barros, L.; Food Chem. 2007, 100, 1511.

100. Saura-Calixto, F.; Goñi, I.; Food Chem. 2006, 94, 442.

101. Osada, Y.; Shibamoto, T.; Food Chem. 2006, 98, 522.

102. Friedman, M.; J. Agric. Food Chem. 2003, 51, 4504.

103. Stadtman, E. R.; Levine, R. L.; Aminoacids 2003, 25, 207.

104. Marnett, L. J.; Riggins, J. N.; West, J. D.; J. Clin. Invest. 2003, 111, 583.

105. Stadtman, E. R.; Free Radical Res. 2006, 40, 1250.

106. Dalle-Donne, I.; Aldini, G.; Carini, M.; Colombo, R.; Rossi, R.; Milzani, A.; J. Cell Mol. Med. 2006, 10, 389.

107. Steiber, A.; Kerner, J.; Hoppel, C. L.; Molecular Aspects of Medicine 2004, 25, 455.

108. Gulçin, I.; Life Sci. 2006, 78, 803.

109. Soni, M. G.; Burdock, G. A.; Christian, M. S.; Bitle, C. M.; Crea, R.; Food Chem. Toxicol. 2006, 44, 903.

110. Sun, J.; Chu, Y-F.; Wu, X.; Liu, R. H.; J. Agric. Food Chem. 2002, 50, 7449.

111. Krygier, K.; Sosulski, F.; Hogge, L.; J. Agric. Food Chem. 1982, 30, 330.
112. Naczk, M.; Shahidi, F.; J. Chromatogr. 2004, 1054, 95.

113. Huang, D.; Ou, B.; Prior, R. L.; J. Agric. Food Chem. 2005, 53, 1841.

114. Niki, E.; International Union of Biochemistry and Molecular Biology Life 2000, 50, 323

115. Prior, R. L.; Wu, X. L.; Schaich, K.; J. Agric. Food Chem. 2005, 53, 4290.

116. Sies, H.; J. Nutr. 2007, 137, 1493.

117. Magalhães, L. M.; Segundo, M. A.; Reis, S.; Lima, J. F. C.; Anal. Chim. Acta 2008, 613, 1 .

118. Dimitrios, B.; Trends Food Sci. Technol. 2006, 17, 505.

119. Abdille, M. D.; Singh, R. P.; Jayaprakasha, G. K.; Jena, B. S.; Food Chem. 2005, 90, 891.

120. Banerjee, A.; Dasgrupta, N.; De, B.; Food Chem. 2005, 90, 727.

121. Stratil, P.; Klejdus, B.; Kubán, V.; Talanta 2007, 71, 1741.

122. Dastmalchi, K.; Dorman, H.; Kosar, M.; Hiltunen, R.; LWT 2007, 40, 239.

123. Singleton, V. L.; Orthofer, R.; Lamuela-Raventós, R. S.; Methods in Enzymol. 1999, 299, 152.

124. Escarpa, A.; González, M. C.; Anal. Chim. Acta 2001, 427, 119.

125. Valko, M.; Leibfritz, D.; Moncol, J.; Cronin, M.; Mazur, M.; Telser, J.; Int. J. Biochem. Cell Biol. 2007, 39, 44.

126. Ewing, J. P.; Janero, D. R.; Anal. Biochem. 1995, 232, 243.

127. Bandy, B.; Bechara, E. J. H.; J. Bioenerg. Biomem. 2001, 3, 269.

128. Naguib, Y. M.; Anal. Biochem. 1998, 265, 290.

129. Owen, R. W.; Giacosa, A.; Hull, W. E.; Haubner, R.; Spiegelhalder, B.; Bartsch, H.; Eur. J. Cancer 2000, 36, 1235.

130. Owen, R. W.; Spiegelhalder, B., Bartsch, H.; Gut 2000, 46, 225.

131. Owen, R. W.; Mier, W.; Giacosa, A.; Hull, W. E.; Haubner, R.; Spiegelhalder, B.; Bartsch, H.; Food Chem. Toxicol. 2000, 38, 647.

132. Drisko, J.; Chapman, J.; Hunter, V.; Gynecol. Oncol. 2003, 88, 434.

133. Gurer, H.; Ercal, N.; Free Radical Biol. Med. 2000, $29,927$.

134. Hsu, P. C.; Guo, Y. L.; Toxicology 2002, 180, 33.

135. Kaliora, A.; Dedoussis, G.; Schmidt, H.; Atherosclerosis 2006, 187, 1.

136. Lopaczynski, W.; Zeisel, S.; Nutr. Res. 2001, 21, 295.

137. Fuhrman, M. P.; Nutrition 2000, 16, 470.

138. US National Academy of Sciences (USA); Dietary Reference Intakes for Vitamin C, Vitamin E, Selenium and Carotenoids, National Academy Press: Washington DC, 2000.

139. Spencer, J. P. E.; Chem. Soc. Rev., 2009 DOI: 10.1039/b800422f.

140. American Dietetic Association; J. Am. Dietetic Association 1996, 96, 73.

141. Tsao, R.; Khanizadeh, S.; Dale, A.; Can. J. Plant Sci. 2006, 86, 773.

142. Vargas, M.; Pastor, C.; Chiralt, A.; McClements, D. J.; GonzalezMartinez, C.; Crit. Rev. Food Sci. Nutr. 2008, 48, 496

143. Patel, C.; Dadhaniya, P.; Hingorani, L.; Soni, M.G.; Food Chem. Toxicol. 2008, 46, 2728. 